\title{
(1)
}

UNIVERSIDAD PERUANA DE CIENCIAS APLICADAS

\author{
FACULTAD DE NEGOCIOS
}

PROGRAMA ACADÉMICO DE NEGOCIOS INTERNACIONALES

\section{Análisis situacional de las exportaciones de pulpa de tuna congelada peruana al mercado de Estados Unidos durante el periodo 2013-2017}

Tesis

Para optar el título profesional de Licenciado en Negocios Internacionales

Díaz Zúñiga, María Claudia- 0000-0003-0212-7593

López Sánchez, Nataly Maribel - 0000-0002-5183-3382

\section{Asesora}

Prof. Pérez Aponte, María Cecilia - 0000-0002-9988-7312 
A nuestros padres, hermanos y amigos, quienes siempre nos dieron los ánimos para seguir adelante. 


\section{AGRADECIMIENTOS}

A la empresa Selva Industrial S.A.,

Por abrirnos las puertas de su empresa y recibirnos de manera cordial, por su disposición en colaborar con la investigación y ofrecer su tiempo para la realización de la misma.

A los especialistas del sector,

Por compartir sus experiencias y opiniones, por su amabilidad y disposición en atendernos y brindar su apoyo constante.

A nuestra asesora,

Por guiarnos a lo largo del desarrollo de la tesis, por compartir sus conocimientos y sugerencias y por brindarnos en todo momento su apoyo.

A nuestros centros de trabajo,

Por darnos las facilidades para poder elaborar este estudio, por ser flexibles con las jornadas laborales con el fin de animarnos a contribuir con la creación de conocimiento.

A nuestros familiares y amigos,

Por comprender los esfuerzos que conllevaron la realización de esta investigación, por darnos el aliento para seguir continuando y acompañarnos hasta su término. 


\section{RESUMEN}

El presente trabajo de investigación tiene como propósito realizar un análisis situacional de las exportaciones de pulpa de tuna congelada peruana al mercado de Estados Unidos durante el periodo 2013-2017.

Por ello en el primer capítulo, se realiza un repaso de la literatura que va desde el origen, definición y producción del fruto de la tuna; hasta los procesos que conlleva la exportación de esta. Por otro lado, se estudia la situación del mercado estadounidense, ya que este ha sido el destino de exportación por excelencia de la pulpa de tuna peruana congelada.

El segundo capítulo aborda la metodología de investigación, la cual describe los objetivos, problemas e hipótesis; así como también a los grupos de actores a entrevistar. Para la estructuración de la información hemos utilizado como guía el PENX 2025.

El tercer capítulo muestra el análisis de datos y resultados de cada grupo de actores de acuerdo con la segmentación realizada y en el cuarto capítulo se discuten los resultados obtenidos.

Finalmente, en el quinto capítulo se describen las conclusiones y recomendaciones de la investigación.

Palabras claves: tuna, oferta exportable, Estados Unidos, organización, alianza 


\section{ABSTRACT}

The purpose of this research is to develop a situational analysis of Peruvian frozen prickly pear puree exports to the US market during period 2013-2017.

Therefore, the first chapter reviews the literature which goes from the origin, definition and production of the prickly pear fruit to the processes that entails the export of the final product. On the other hand, it is also reviewed the situation of the US market since it has been the export destination par excellence of the Peruvian frozen prickly pear pulp.

The second chapter approaches the research methodology, which describes the objectives, problems and hypotheses; as well as the groups of actors interviewed. For the structuring of the information we have used the PENX 2025 as a guideline.

The third chapter shows the data analysis and results of each group of actors according to the segmentation and in the fourth chapter obtained results are discussed.

Finally, the fifth chapter describes the conclusions and recommendations of our investigation.

Key words: prickly pear, exportable supply, United States of America, organization, alliance 


\section{ÍNDICE}

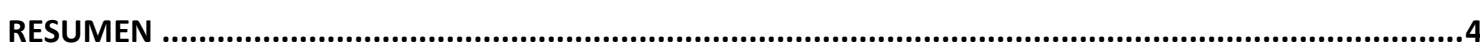

ABSTRACT

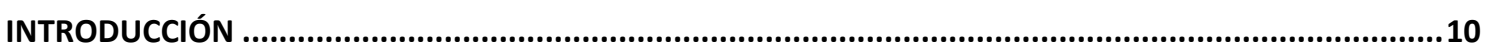

CAPÍTULO I - MARCO TEÓRICO

1.1. DESEMPEÑO DE LAS AGROEXPORTACIONES PERUANAS 2013-2017 .................................................12

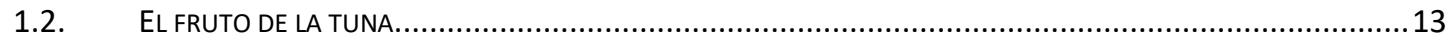

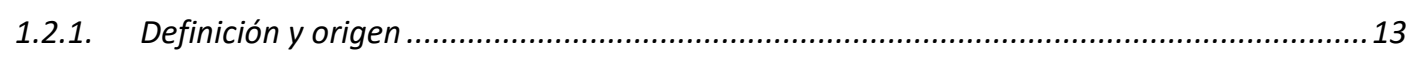

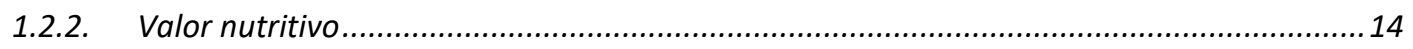

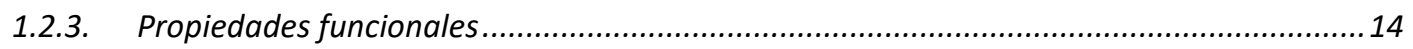

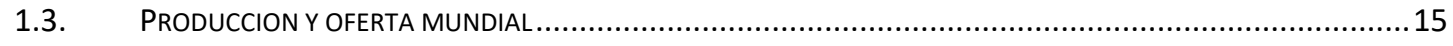

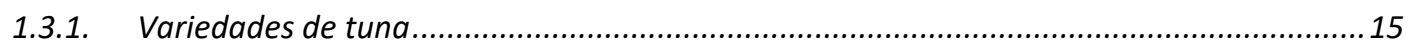

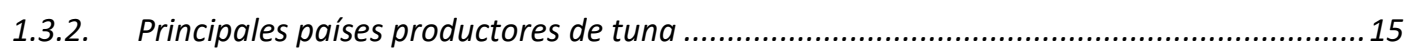

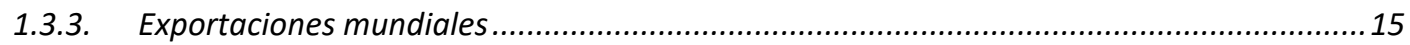

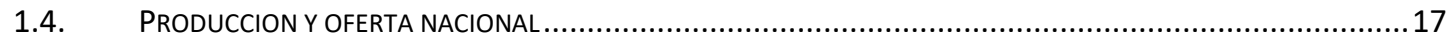

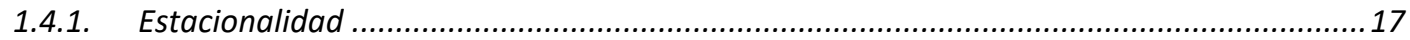

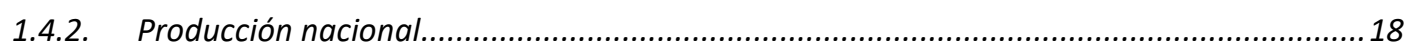

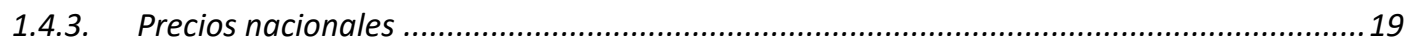

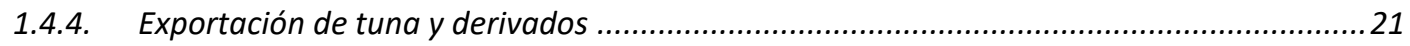

1.5. ANALISIS DE LA PULPA DE TUNA CONGELADA EN EL MERCADO ESTADOUNIDENSE ...................................26

1.5.1. Características del mercado estadounidense ................................................................26

1.5.2. Acuerdo de Promoción Comercial Perú-Estados Unidos....................................................27

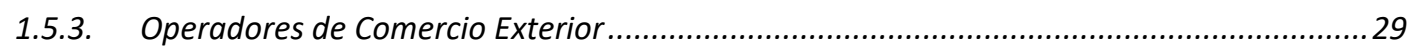

1.5.4. Exportaciones peruanas de pulpa de tuna congelada a Estados Unidos...........................30

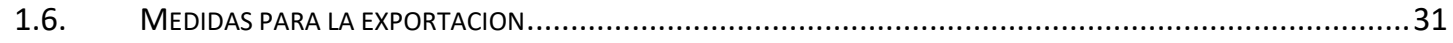

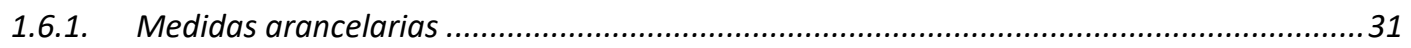

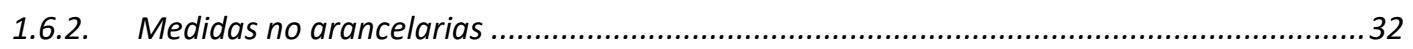

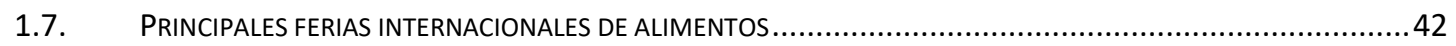

CAPÍTULO II - METODOLOGÍA DE INVESTIGACIÓN......................................................................43

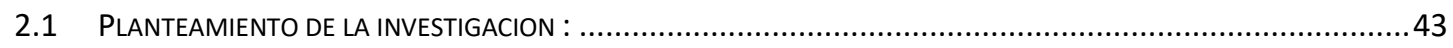

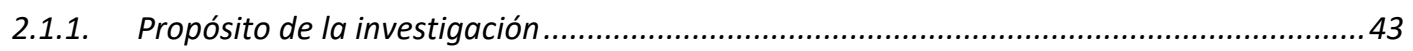

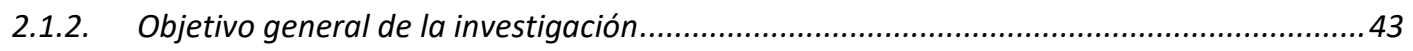

2.1.3. Objetivos especificos de la investigación ....................................................................43

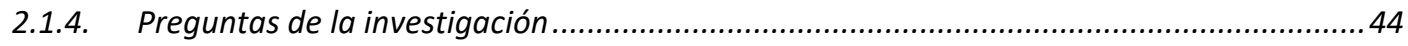

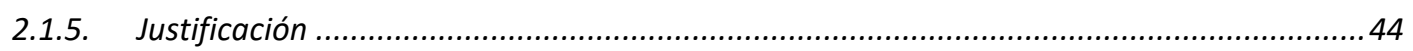


2.1.6. Hipótesis de la investigación...............................................................................45

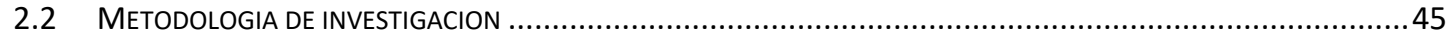

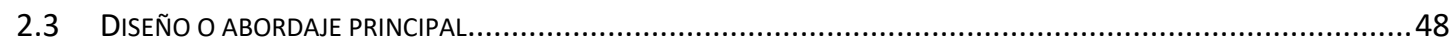

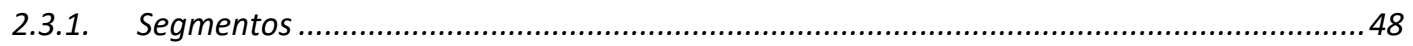

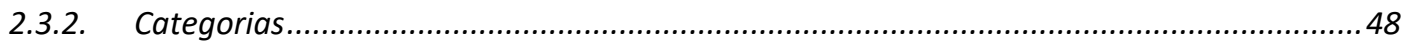

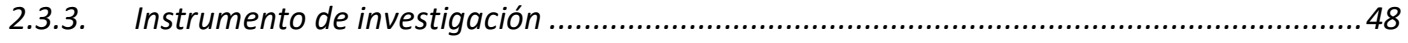

2.3.4. Identificación de la estructura de la entrevista...........................................................49

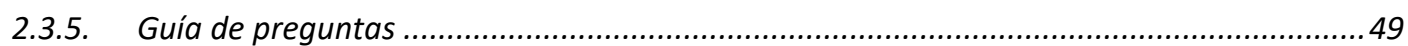

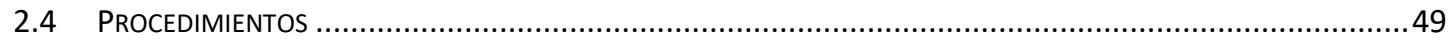

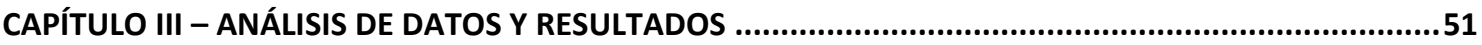

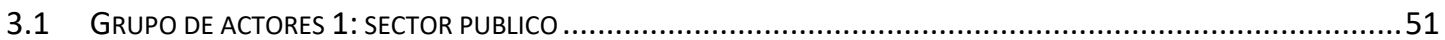

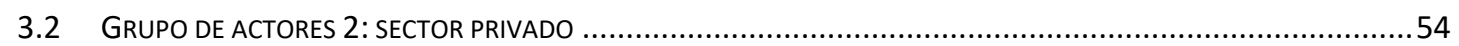

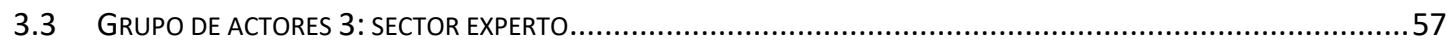

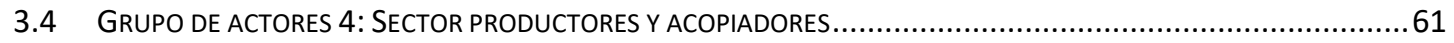

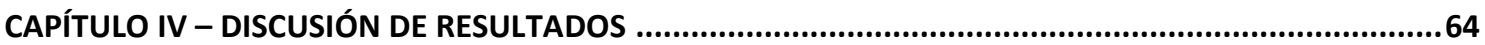

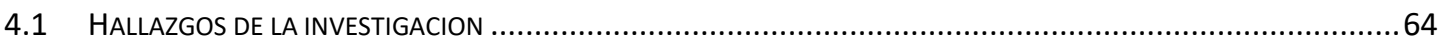

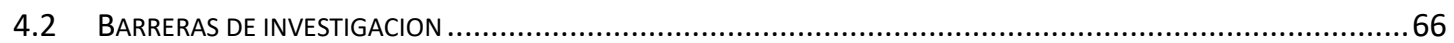

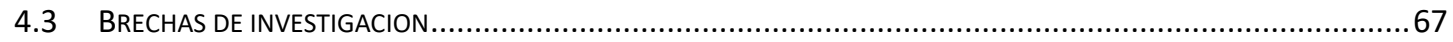

CAPÍTULO V - CONCLUSIONES Y RECOMENDACIONES .............................................................68

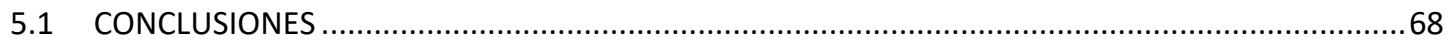

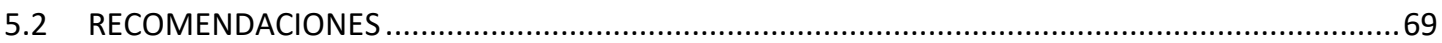

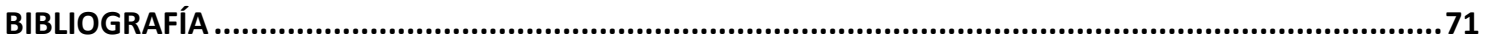

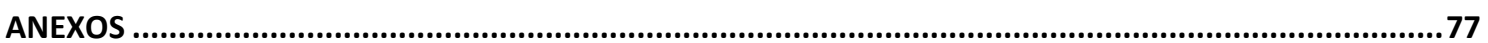




\section{ÍNDICE DE TABLAS}

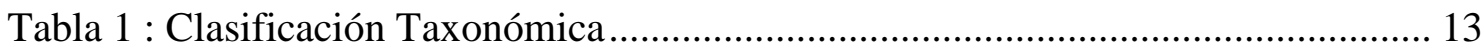

Tabla 2 : Producción de tuna (t) en el departamento de Ayacucho, Perú......................... 18

Tabla 3 : Producción de tuna (t) en el departamento de Cuzco, Perú............................... 18

Tabla 4 : Producción de tuna (t) en el departamento de Lima, Perú. .............................. 19

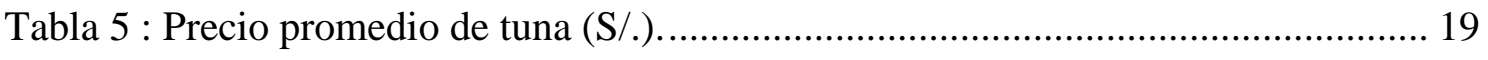

Tabla 6 : Volumen (t) según producto y procedencia (departamento de Ayacucho) ..... 20

Tabla 7 : Volumen (t) según producto y procedencia (departamento de Lima)............. 21

Tabla 8: Perú: exportaciones pulpa de tuna congelada al mercado de Estados Unidos

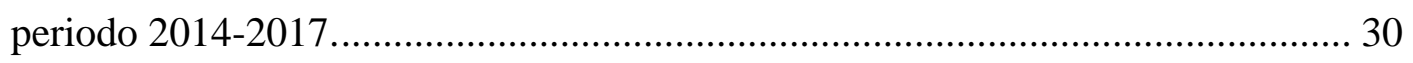

Tabla 9: Perú: procesos considerados para productos de origen vegetal en el aspecto

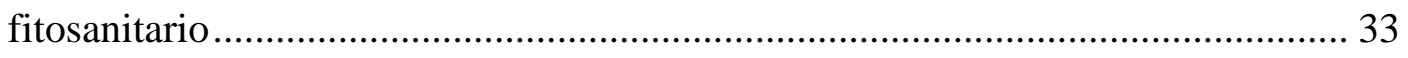

\section{ÍNDICE DE GRAFICOS}

Figura 1. Exportaciones en US\$ millones sector agro no tradicional y tradicional periodo 2013-2017. Adaptado de "Exportaciones Perú 2017", por Promperú, 2017

Figura 2. México : exportaciones de tuna fresca en términos de valor FOB periodo 2015-2017. 16

Figura 3. México : exportaciones de pulpa de tuna congelada en términos de valor FOB periodo 2015-2017.

Figura 4. Estacionalidad de la tuna. Adaptado del brochure de la empresa Selva Industrial S.A., 2011 18

Figura 5. Exportaciones de tuna fresca en términos de valor FCA periodo 2013-2017.22 Figura 6. Exportaciones de tuna fresca en términos de peso neto $(\mathrm{kg})$ periodo 20132017. 22

Figura 7. Exportaciones de tuna fresca en términos de precio promedio (US\$) periodo 2013-2017.

Figura 8. Exportaciones pulpa de tuna congelada en términos de valor FOB(US\$) periodo 2014-2017. 
Figura 9. Exportaciones pulpa de tuna congelada en términos de peso neto(kg) periodo 2014-2017. 24

Figura 10. Exportaciones pulpa de tuna congelada en términos precio prom. (US\$) periodo 2014-2017. 25

Figura 11. Clasificación arancelaria de la pulpa de tuna congelada. Adaptado de Arancel de Aduanas 2017, por SUNAT, 2017 32 


\section{INTRODUCCIÓN}

Cuando los españoles arribaron a la isla de La Española (actualmente Haití y República Dominicana) en el Mar Caribe, los nativos les mostraron frutos rojos de Opuntia, denominados "tuna" derivada de la palabra tun en la lengua nativa. Los primeros europeos que llegaron al continente americano apreciaron la importancia -cultural y económica- de los opuntias en el complejo mundo prehispánico (Organización de las Naciones Unidas para la Alimentación [FAO], 2017).

Los españoles llevaron el nopal - y seguramente también los insectos de D. coccus - a Perú, aunque ya en nuestro país se usaban otras cochinillas para la obtención de pigmento en la era prehispánica (Organización de las Naciones Unidas para la Alimentación [FAO], 2017).

Como es de conocimiento a nivel internacional, el Perú se ha caracterizado desde tiempos inmemorables por su amplia biodiversidad en flora y fauna gracias a los distintos microclimas que facilitan el cultivo de una infinidad de productos en cada una de sus tres regiones. Es así como es posible destacar el cultivo de la tuna en la región Sierra de nuestro país.

Para el caso específico de la tuna, este fruto se desarrolla principalmente en zonas áridas o semi-áridas y no requiere grandes cantidades de agua para el riego de los cultivos. En la actualidad el consumo de la tuna ha mostrado un crecimiento continuo en todo el mundo por sus valores nutricionales, como también por sus características sensoriales, proporcionados por el aroma y sabor característicos de la especie, siendo importante hacer extensivo el consumo de frutos y hojas de tuna por sus propiedades antioxidantes 
cuyo potencial ha sido reconocido por la Organización de las Naciones Unidas para la Alimentación (Gerencia Regional Agraria La Libertad, 2009).

A nivel nacional, los principales departamentos productores de tuna son Ayacucho, Cusco y Lima (SIICEX, 2008). Es este último departamento el cual ha mostrado un crecimiento sostenido durante el periodo analizado de tres años.

Apostar por el cultivo de la tuna y la exportación con un valor agregado de este fruto, sin duda, beneficia a todos los actores de la cadena de valor, especialmente a los agricultores y empresas exportadoras.

A través de las estadísticas de comercio exterior ha sido posible evidenciar exportaciones de pulpa de tuna congelada con un crecimiento sostenido durante el periodo analizado y teniendo como principal destino el mercado de Estados Unidos. Es por ello que, a través del presente trabajo de investigación se busca realizar un análisis situacional de las exportaciones de pulpa de tuna congelada peruana al mercado de Estados Unidos durante el periodo 2013-2017. 


\section{CAPÍTULO I - MARCO TEÓRICO}

\subsection{Desempeño de las agroexportaciones peruanas 2013-2017}

De acuerdo con el reporte emitido por Promperú (2017), el sector agroexportador ha presentado un récord histórico de exportaciones durante el período 2013-2017. Tal como se muestra en la figura 1, las exportaciones del sector agro han sido el segundo generador de divisas mostrando un comportamiento de crecimiento continuo.

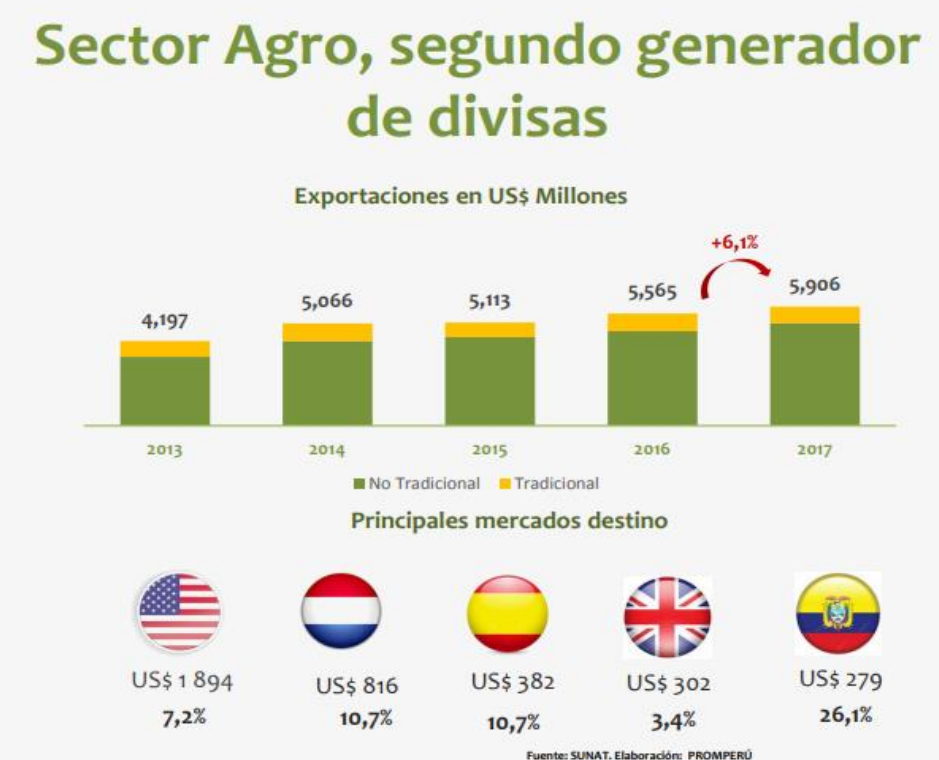

Figura 1. Exportaciones en US\$ millones sector agro no tradicional y tradicional periodo 2013-2017. Adaptado de "Exportaciones Perú 2017", por Promperú, 2017

De acuerdo con el portal América Economía (2018), entre los productos más destacados encontramos las uvas frescas, paltas frescas, espárragos frescos y preparados, arándanos frescos, mangos frescos, bananas tipo Cavendish Valery, cacao en grano, demás cítricos, quinua, alcachofas preparadas, entre otros. 


\subsection{El fruto de la tuna}

\subsubsection{Definición y origen}

El nopal (tuna) es una planta oriunda de México, pertenece a la familia de las cactáceas y mide tres metros de altura aproximadamente. Cuenta con tallos aplastados y carnosos, está formado por paletas ovales de 30 a $40 \mathrm{~cm}$ de longitud y $20 \mathrm{~cm}$ de anchura. Sus hojas son espinosas y cuentan con flores grandes al borde de los tallos (Real Academia Española [RAE], 2017). El fruto tiene forma cilíndrica de color verde y cuando madura toma diferentes colores, el interior es gelatinoso y contiene numerosas semillas (Organización de las Naciones Unidas para la Alimentación [FAO], 2006).

La tuna es conocida mundialmente como una fruta exótica por su apariencia poco usual, de forma ovalada con espinas y piel gruesa (Portal Frutícola, 2013).

La clasificación taxonómica de la tuna se describe a continuación:

Tabla 1 : Clasificación Taxonómica

\begin{tabular}{|ll|}
\hline Reino & Vegetal \\
Subreino & Embryophyta \\
División & Angioserma \\
Clase & Dicotiledoneae \\
Subclase & Dialipetalas \\
Orden & Opuntiales \\
Familia & Cactaceae \\
Tribu & Opuntiae \\
Subfamilia & Opuntioideae \\
Género & Opuntia \\
Subgénero & Platyopuntia \\
Especie & Varios nombres \\
\hline
\end{tabular}

Nota : Adaptado de "Nopal Verdura", por Instituto Nacional de Ecología y Cambio Climático (INECC), 2007 


\subsubsection{Valor nutritivo}

De acuerdo con el Boletín de Servicios Agrícolas de la Organización de las Naciones Unidas para la Alimentación [FAO], (2006); la tuna contiene un alto valor nutritivo muy similar al de otros frutos como la manzana, ciruela y cereza. Sin embargo, se destaca el contenido en sólidos solubles siendo esta fruta apta para diversos usos como la concentración y deshidratación, ya que aprovecha la disminución de la actividad del agua y el incremento de azúcares como medio de preservación.

Por otro lado, el fruto de la tuna es una gran fuente de potasio $(217 \mathrm{mg} / 100 \mathrm{~g})$ y presenta un reducido contenido de sodio; pudiendo ser consumido por personas con problemas renales o de hipertensión. Asimismo, mencionar que, la tuna contiene calcio y fósforo, vitaminas fundamentales para la formación de los huesos (Organización de las Naciones Unidas para la Alimentación [FAO], 2006).

\subsubsection{Propiedades funcionales}

La tuna, además de poseer un valor nutritivo, es también considerada un alimento funcional, ya que el consumo de ésta proporciona beneficios que fortalecen la salud y ayuda a prevenir enfermedades (Organización de las Naciones Unidas para la Alimentación [FAO], 2006).

Según la Organización de las Naciones Unidas para la Agricultura y la Alimentación (FAO, 2006) la fibra, es uno de los componentes que más destacan y a la vez es uno de los más estudiados, ya que existe un vínculo bastante estrecho entre éste y la salud porque ayuda al control del colesterol y a la prevención de enfermedades como la diabetes y obesidad.

Otro componente, son los pigmentos que se encuentran en el fruto y destacan por su poder antioxidante, la misma función cumple la pulpa ya que es rica en vitamina $C$; por lo que su consumo evita el envejecimiento de los tejidos (Organización de las Naciones Unidas para la Alimentación [FAO], 2006). 


\subsection{Producción y oferta mundial}

\subsubsection{Variedades de tuna}

La tuna es un fruto que presenta una diversidad de colores y sabores. De acuerdo con el portal SIICEX (2008), podemos encontrar las siguientes variedades:

- Tuna blanca: sus frutos son de color verde claro, muy jugosos y dulces.

- Tuna morada: tiene buena calidad de fruto.

- Tuna amarilla: es la mejor tuna para la producción de cochinilla.

\subsubsection{Principales países productores de tuna}

De acuerdo con la Organización de las Naciones Unidas para la Alimentación y la Agricultura; el fruto de la tuna es originario de México (mayor productor mundial). En América también se cultiva en Chile, Perú y Estados Unidos. En Europa se localiza en España e Italia y en África se encuentra principalmente en Marruecos, Túnez y Egipto (Organización de las Naciones Unidas para la Alimentación [FAO], s.f.).

\subsubsection{Exportaciones mundiales}

Para el presente punto, vamos a analizar las exportaciones mundiales de tuna del principal país productor México. Para este estudio se tenía previsto también analizar las exportaciones de tuna de Italia, sin embargo, no fue posible encontrar data actualizada en el portal de inteligencia comercial Veritrade.

\section{Exportaciones mundiales de México}

Tal como se ha mencionado anteriormente, México es el principal país productor de tuna. En dicho país, la tuna se cosecha entre los meses de abril a noviembre; sin 2embargo, la mayor producción se concentra en julio, agosto y septiembre en los que se 
obtiene el 85\% de la producción total (Central de Abasto de la Ciudad de México, 2016).

De acuerdo con Veritrade (2018), la tuna mexicana actualmente se exporta en dos diferentes presentaciones las cuales son: tuna fresca (P.A. 0810.90.99) y pulpa de tuna congelada (P.A.2007.99.99/2008.99.99).

Para efectos de la presente investigación, analizaremos el desempeño del valor FOB expresado en miles de dólares de las dos presentaciones mencionadas anteriormente.

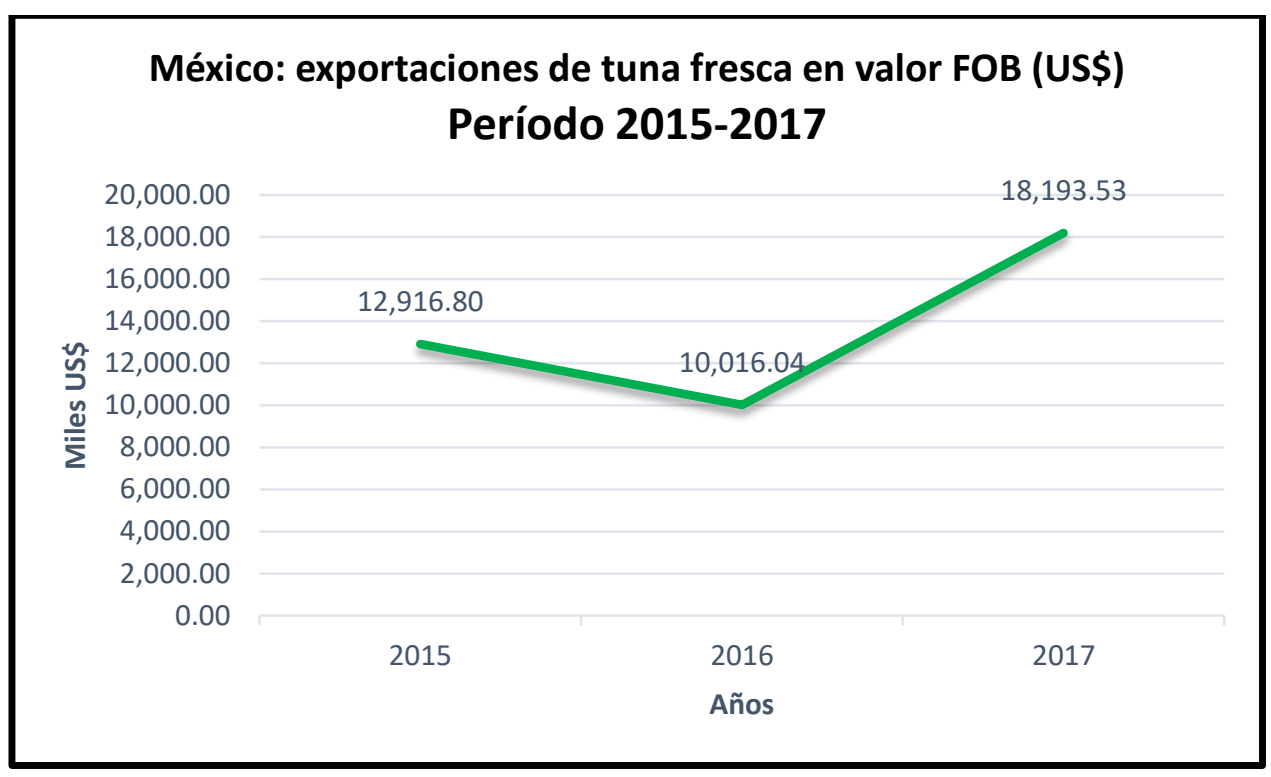

Figura 2. México : exportaciones de tuna fresca en términos de valor FOB periodo 2015-2017. Adaptado de Veritrade, 2018

Tal como se muestra en el cuadro, los valores de exportación en términos FOB México de la tuna fresca durante el período 2015-2017 ha sido variable con una tendencia final de crecimiento alcanzando en el año 2017 el valor total de US\$ 18,193.53.

Por otro lado, analizando el destino de las exportaciones mexicanas de tuna fresca se concluye que Estados Unidos es el único mercado de exportación hasta el momento y las variedades de tuna roja y verde las preferidas por este mercado. 


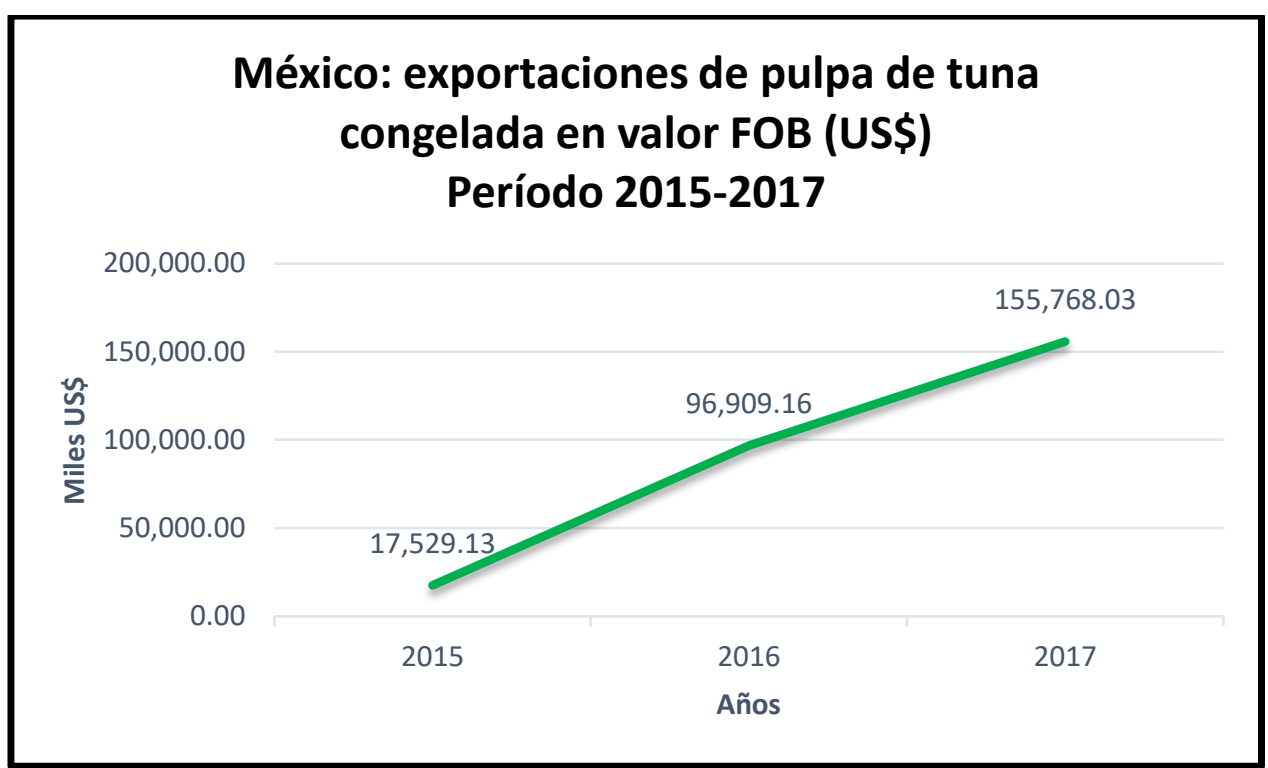

Figura 3. México : exportaciones de pulpa de tuna congelada en términos de valor FOB periodo 2015-2017.

Adaptado de Veritrade, 2018

La pulpa de tuna procesada proveniente de México se exporta totalmente en la presentación congelada. En Veritrade (2018) se pueden obtener datos a partir del año 2015 en adelante y podemos observar que durante el periodo analizado se presenta una tendencia de crecimiento. Por otro lado, los principales mercados de destino son Estados Unidos, Alemania y Holanda.

\subsection{Producción y oferta nacional}

\subsubsection{Estacionalidad}

De acuerdo con el Ing. agrónomo Renzo Gómez, gerente comercial de la empresa Selva Industrial S.A., la estacionalidad de la tuna es relativamente corta y por ello se debe aprovechar al máximo su producción.

Los meses pueden variar de acuerdo con diversas razones climáticas, sin embargo, la estacionalidad empieza en el mes de diciembre hasta mediados de abril. La temporada peruana de cosecha de tuna no se cruza con la temporada de la tuna mexicana, lo que confiere una oportunidad de posicionamiento. 


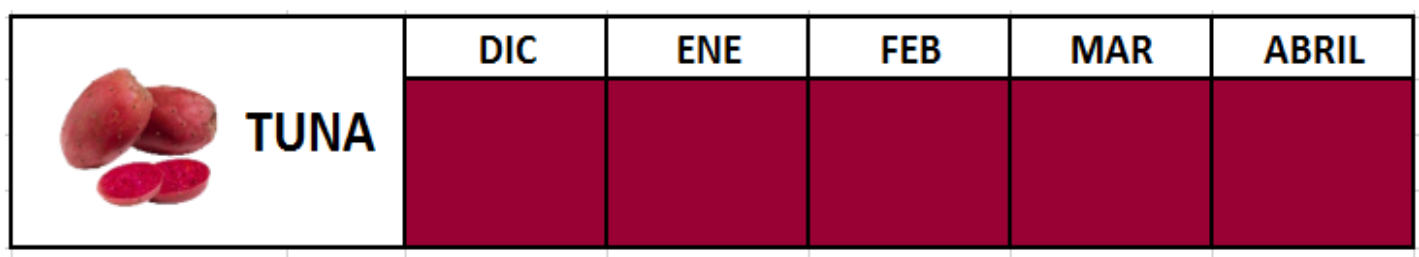

Figura 4. Estacionalidad de la tuna. Adaptado del brochure de la empresa Selva Industrial S.A., 2011

\subsubsection{Producción nacional}

Según el portal SIICEX (2008), las principales zonas de producción de tuna son los departamentos de Ayacucho, Lima y Cuzco.

A continuación, se detallan los volúmenes de producción de tuna en los principales departamentos productores de nuestro país durante el período 2014-2016.

\section{Departamento de Ayacucho}

Tabla 2 : Producción de tuna (t) en el departamento de Ayacucho, Perú

\begin{tabular}{|c|r|}
\hline \multicolumn{2}{|c|}{ PRODUCCIÓN (t) } \\
\hline Años & AYACUCHO \\
\hline $\mathbf{2 0 1 4}$ & 15,907 \\
\hline $\mathbf{2 0 1 5}$ & 19,093 \\
\hline $\mathbf{2 0 1 6}$ & 18,180 \\
\hline
\end{tabular}

Adaptado de "Serie de estadísticas de producción agrícola (SEPA)", por Ministerio de Agricultura y Riego (MINAGRI), 2015

\section{Departamento de Cuzco}

Tabla 3 : Producción de tuna (t) en el departamento de Cuzco, Perú

\begin{tabular}{|c|r|}
\hline \multicolumn{2}{|c|}{ PRODUCCIóN (t) } \\
\hline Años & \multicolumn{1}{c|}{ CUZCO } \\
\hline $\mathbf{2 0 1 4}$ & 24,944 \\
\hline $\mathbf{2 0 1 5}$ & 27,773 \\
\hline 2016 & 22,867 \\
\hline
\end{tabular}

Adaptado de "Serie de estadísticas de producción agrícola (SEPA)", por Ministerio de Agricultura y Riego (MINAGRI), 2015 


\section{Departamento de Lima}

Tabla 4 : Producción de tuna (t) en el departamento de Lima, Perú.

\begin{tabular}{|c|r|}
\hline \multicolumn{2}{|c|}{ PRODUCCIÓN (t) } \\
\hline Años & \multicolumn{1}{c|}{ LIMA } \\
\hline $\mathbf{2 0 1 4}$ & 12,436 \\
\hline $\mathbf{2 0 1 5}$ & 13,636 \\
\hline $\mathbf{2 0 1 6}$ & 14,088 \\
\hline
\end{tabular}

Adaptado de "Serie de estadísticas de producción agrícola (SEPA)", por Ministerio de Agricultura y Riego (MINAGRI), 2015

A través de los gráficos es posible evidenciar el comportamiento de la producción de tuna en los principales departamentos productores de nuestro país. El departamento de Lima es la zona de producción que ha presentado un crecimiento sostenido en términos de toneladas durante el periodo 2014-2016.

\subsubsection{Precios nacionales}

A continuación, se detalla el precio promedio que registró la tuna en sus tres principales variedades en el Mercado Mayorista de Lima.

Tabla 5 : Precio promedio de tuna (S/.).

\begin{tabular}{|c|c|c|c|}
\hline \multirow{2}{*}{ Año } & Tuna Amarilla & Tuna Blanca & $\begin{array}{c}\text { Tuna Morada I } \\
\text { Rosada }\end{array}$ \\
\cline { 2 - 4 } & $\begin{array}{c}\text { Precio Promedio } \\
\text { (SI. x Kg., S/. x Lt. } \\
\text { o Sl. x Unid.) }\end{array}$ & $\begin{array}{c}\text { Precio Promedio } \\
\text { (SI. x Kg., SI. x Lt. o } \\
\text { S/. x Unid.) }\end{array}$ & $\begin{array}{c}\text { Precio Promedio } \\
\text { (S/. x Kg., SI. x Lt. o } \\
\text { S/. x Unid.) }\end{array}$ \\
\hline 2014 & 3.28 & 3.30 & 3.26 \\
\hline 2015 & 3.30 & 3.33 & 3.30 \\
\hline 2016 & 3.10 & 3.17 & 3.10 \\
\hline
\end{tabular}

Adaptado de "Mercados Mayoristas de Lima Metropolitana" por Ministerio de Agricultura y Riego (MINAGRI) - Área de comercialización, 2017 
Como se puede apreciar en el cuadro, el precio del 2017 para la tuna amarilla y blanca mejoró en comparación al año anterior, es más la primera igualó el precio del año 2014. La tuna morada/rosada es un caso aparte, ya que al transcurrir los años el precio ha ido mejorando, siendo el 2017 el año con mejor desempeño para esta variable con s/3.32 por kilo como precio promedio.

Siguiendo con el análisis de esta fruta, a continuación, se detallará el volumen que ingresó al mercado mayorista de la capital, de acuerdo con el lugar de procedencia en los últimos 4 años.

Tabla 6 : Volumen (t) según producto y procedencia (departamento de Ayacucho)

\begin{tabular}{|c|c|c|c|c|c|c|}
\hline \multirow{2}{*}{ Año } & \multicolumn{2}{|c|}{$\begin{array}{c}\text { Tuna Amarilla } \\
\text { Volumen (t) }\end{array}$} & \multicolumn{2}{c|}{$\begin{array}{c}\text { Tuna Blanca } \\
\text { Volumen (t) }\end{array}$} & \multicolumn{2}{c|}{$\begin{array}{c}\text { Tuna Morada } \\
\text { Rosada } \\
\text { Volumen (t) }\end{array}$} \\
\cline { 2 - 7 } & Total & Huanta & Total & Huanta & Total & Huanta \\
\hline 2014 & 41.8 & 41.8 & 928.1 & 928.1 & 35.9 & 35.9 \\
\hline 2015 & 49.8 & 49.8 & 146.3 & 146.3 & 31.9 & 31.9 \\
\hline 2016 & 0.0 & 0.0 & 18.0 & 18.0 & 0.0 & 0.0 \\
\hline 2017 & 0.0 & 0.0 & 0.0 & 0.0 & 0.0 & 0.0 \\
\hline
\end{tabular}

Adaptado de "Mercados Mayoristas de Lima Metropolitana" por Ministerio de Agricultura y Riego (MINAGRI) - Área de comercialización, 2017

El cuadro evidencia que el ingreso de tuna procedente del departamento de Ayacucho en sus tres variedades ha decrecido, al punto que en el 2017 no registró ninguna cifra. El año con mayor desempeño fue el 2014, y la única zona de la cual se abastecía era Huanta. 
Tabla 7 : Volumen (t) según producto y procedencia (departamento de Lima)

\begin{tabular}{|c|c|c|c|c|c|c|c|c|c|c|c|c|}
\hline \multirow{2}{*}{ Año } & \multicolumn{4}{|c|}{$\begin{array}{c}\text { Tuna Amarilla } \\
\text { Volumen ( } t \text { ) }\end{array}$} & \multicolumn{4}{c|}{$\begin{array}{c}\text { Tuna Blanca } \\
\text { Volumen (t) }\end{array}$} & \multicolumn{4}{c|}{$\begin{array}{c}\text { Una Morada / Rosada } \\
\text { Volumen (t) }\end{array}$} \\
\cline { 2 - 15 } & Total & Huarochiri & Cañete & Huaral & Total & Huarochiri & Cañete & Huaral & Total & Huarochiri & Cañete & Huaral \\
\hline 2014 & 3811.6 & 1688.7 & 2122.9 & 0.0 & 2716.0 & 2550.4 & 165.6 & 0.0 & 3274.1 & 1738.4 & 1535.8 & 0.0 \\
\hline 2015 & 4050.5 & 1069.6 & 2980.9 & 0.0 & 4045.3 & 3671.9 & 373.4 & 0.0 & 3375.9 & 1228.4 & 2140.9 & 6.6 \\
\hline 2016 & 3734.7 & 1002.4 & 2728.4 & 4.0 & 4240.0 & 4240.0 & 0.0 & 0.0 & 3139.0 & 1048.5 & 2090.5 & 0.0 \\
\hline 2017 & 3175.5 & \multicolumn{3}{|c|}{ Adaptado de "Mercados Mayoristas de Lima Metropolitana" por Ministerio de } & 461.5 & 0.0 \\
\hline
\end{tabular}

Agricultura y Riego (MINAGRI) - Área de comercialización, 2017

Con lo que respecta a Lima, el 2015 fue el año en que se registró el mayor volumen para la tuna amarilla y morada, y el 2016 para la blanca. Sin embargo, la tendencia de aprovisionamiento en general es a la baja. Dentro de las zonas productoras destaca Huarochirí con la tuna blanca y Cañete con la tuna morada y amarilla.

\subsubsection{Exportación de tuna y derivados}

De acuerdo con el portal de investigación de mercados, Veritrade (2018), en nuestro país actualmente se está exportando la tuna en dos presentaciones: tuna fresca y pulpa de tuna congelada.

A continuación, analizaremos el desempeño que han mostrado estos dos tipos de presentaciones durante el período 2013-2017 en término de valor FOB, peso neto y precio promedio en dólares americanos.

Las exportaciones de tuna fresca se encuentran comprendidas dentro de la partida arancelaria 0810.90.90.00. Esta partida no es específica por lo que es necesario filtrar las exportaciones con el fin de ubicar los envíos de tuna fresca. De acuerdo con las estadísticas, la tuna fresca se exporta vía aérea y los principales mercados de destino son Alemania y Francia. 


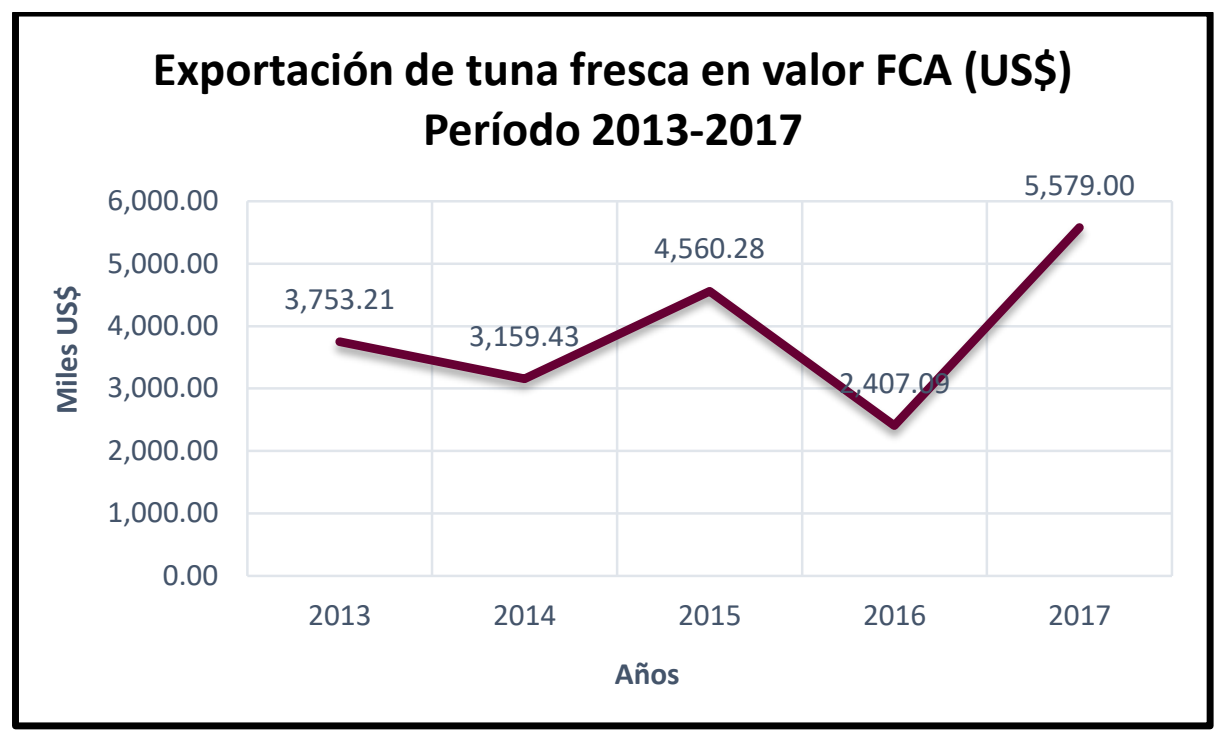

Figura 5. Exportaciones de tuna fresca en términos de valor FCA periodo 2013-2017.

Adaptado de Veritrade, 2018

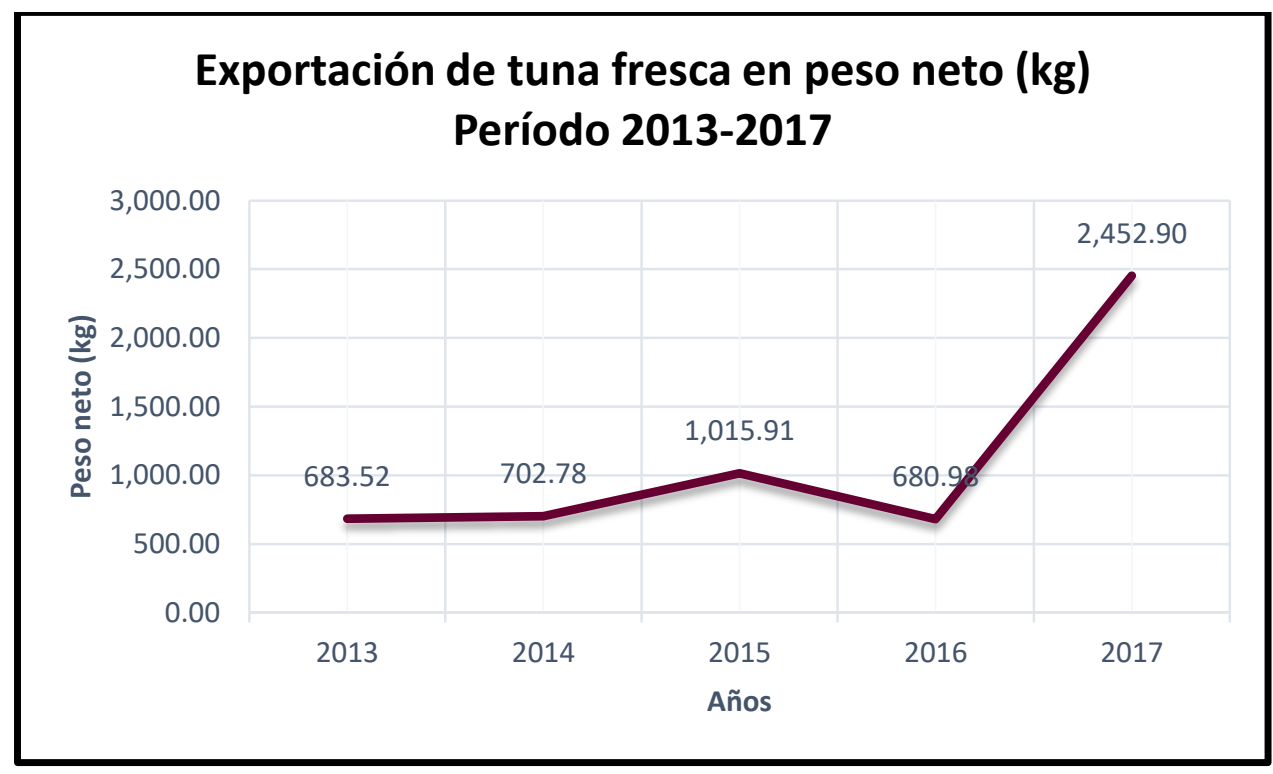

Figura 6. Exportaciones de tuna fresca en términos de peso neto $(\mathrm{kg})$ periodo 2013 2017.

Adaptado de Veritrade, 2018 


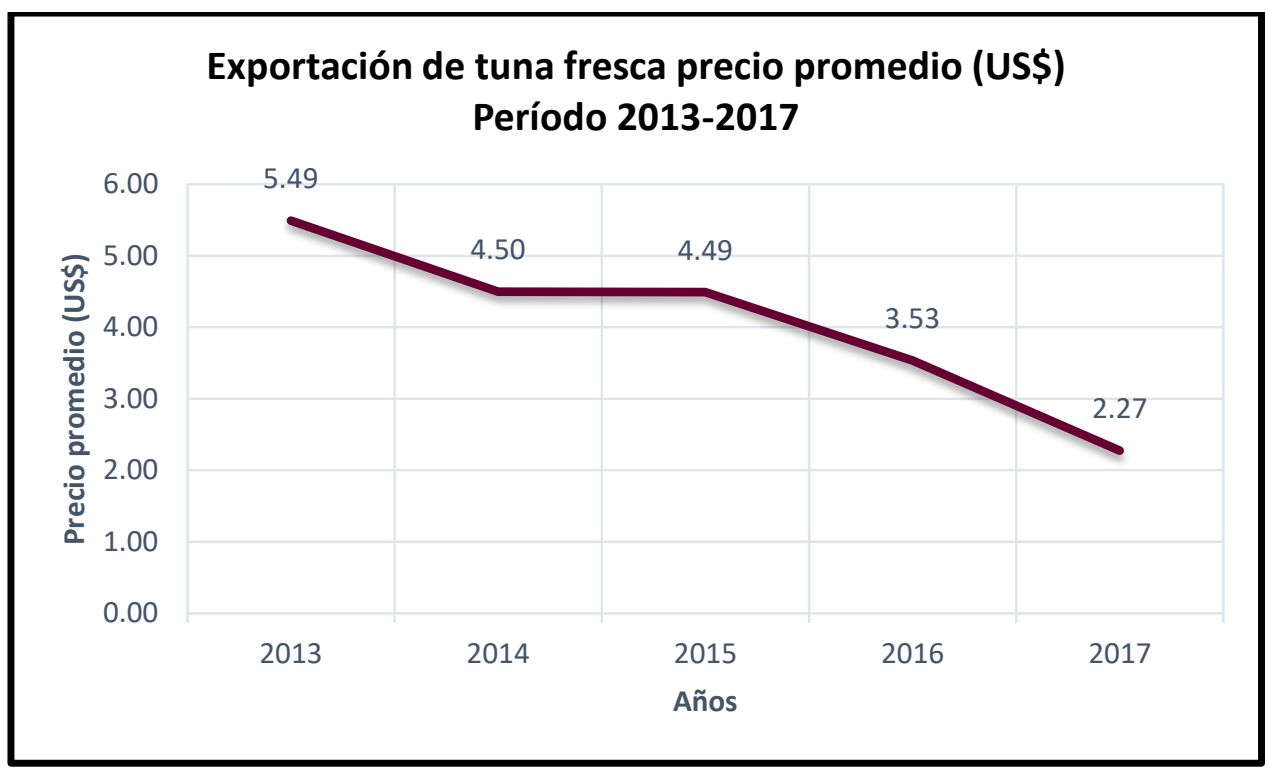

Figura 7. Exportaciones de tuna fresca en términos de precio promedio (US\$) periodo 2013-2017.

\section{Adaptado de Veritrade, 2018}

El comportamiento de las exportaciones de tuna fresca durante el período 2013-2017 muestra variaciones en los tres ámbitos analizados (precio FCA, peso neto y precio promedio). Es importante resaltar el incremento tanto en valor como en peso neto entre los años 2016-2017 causando una caída en el precio promedio.

Por su lado, la exportación de pulpa de tuna congelada se encuentra comprendida dentro de la partida arancelaria 2008.99.90.00. Esta partida tampoco es específica por lo que es necesario filtrar las exportaciones con el fin de ubicar los envíos de pulpa de tuna congelada. De acuerdo con las estadísticas, la pulpa de tuna congelada se exporta vía marítima y el principal mercado de destino es Estados Unidos. 


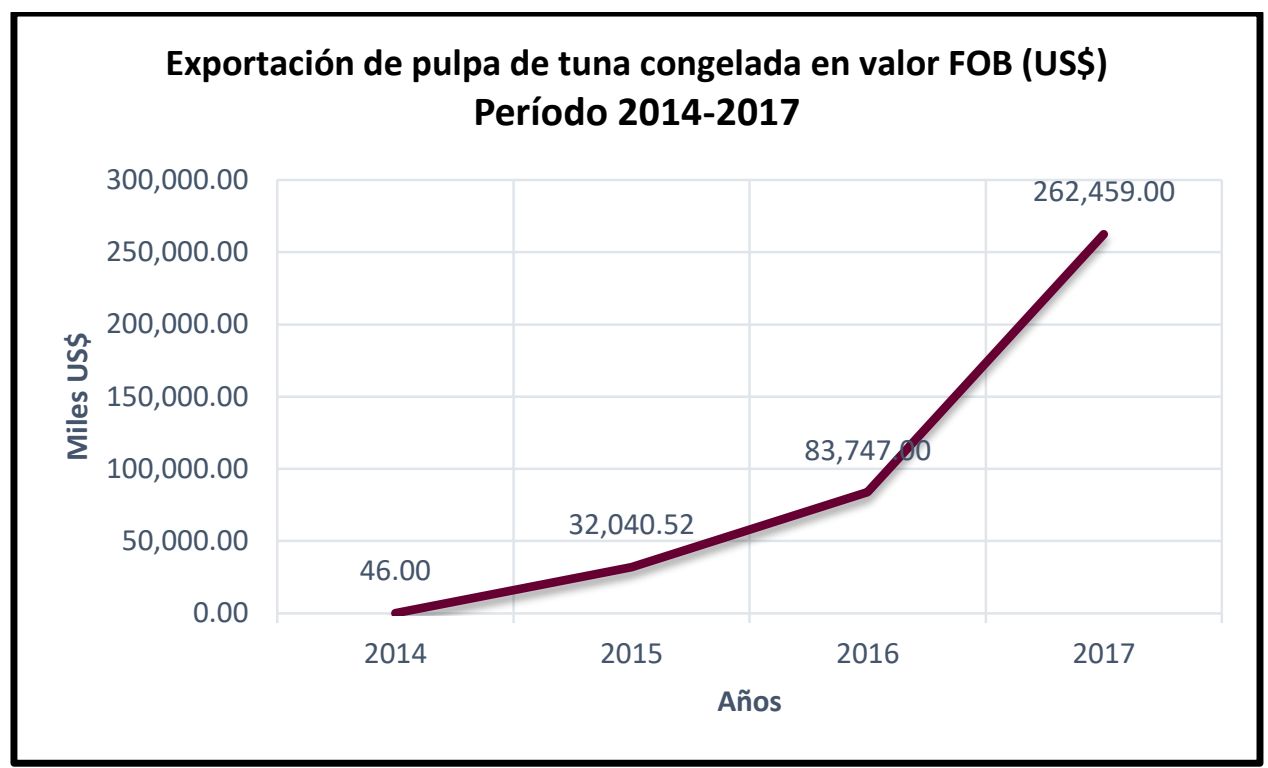

Figura 8. Exportaciones pulpa de tuna congelada en términos de valor FOB(US\$) periodo 2014-2017.

Adaptado de Veritrade, 2018

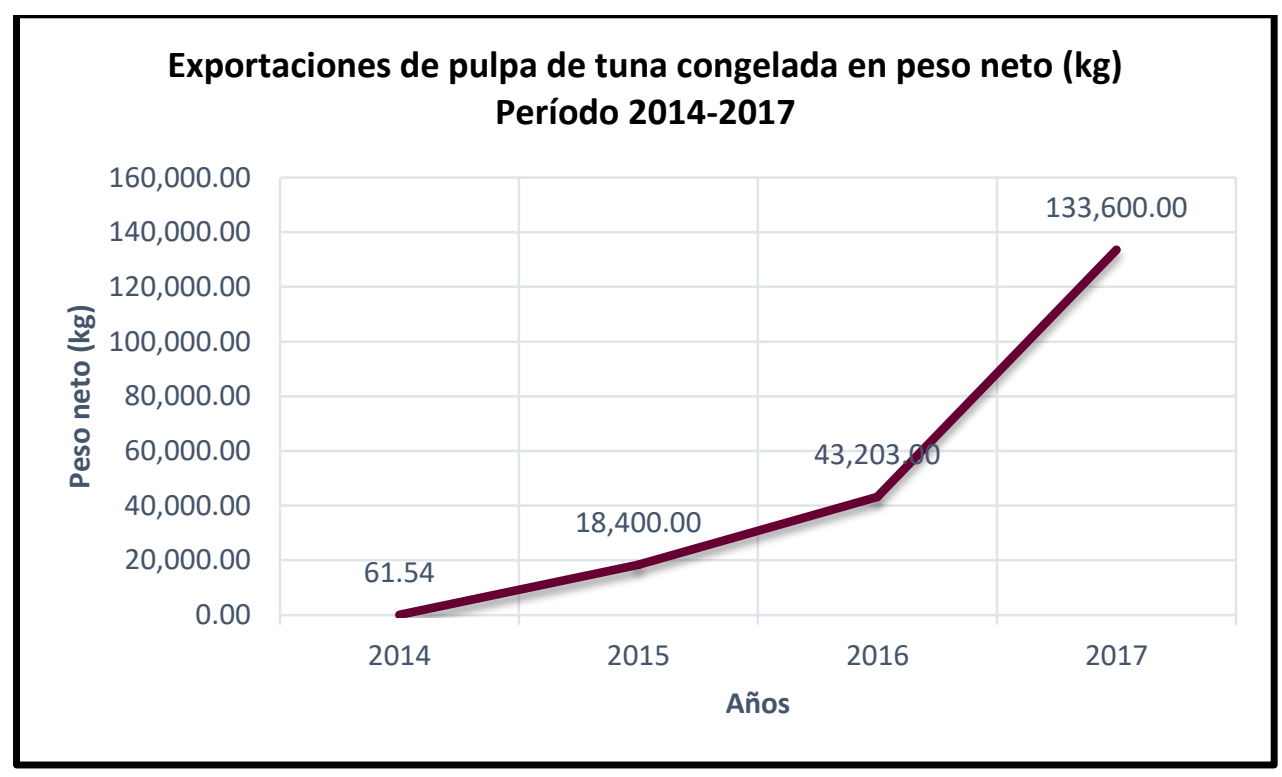

Figura 9. Exportaciones pulpa de tuna congelada en términos de peso neto $(\mathrm{kg})$ periodo 2014-2017.

Adaptado de Veritrade, 2018 


\section{Exportaciones de pulpa de tuna congelada precio promedio (US\$) \\ Período 2014-2017}

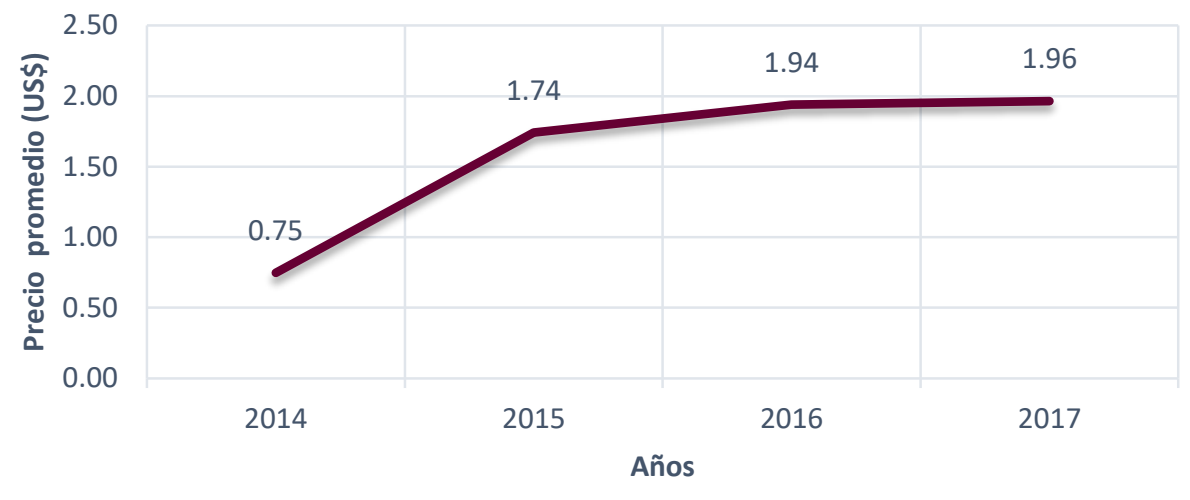

Figura 10. Exportaciones pulpa de tuna congelada en términos precio prom. (US\$) periodo 2014-2017.

\section{Adaptado de Veritrade, 2018}

Es importante señalar que actualmente existe solo una empresa exportadora de pulpa de tuna congelada hacia el mercado de Estados Unidos. Esta empresa es Selva Industrial S.A. cuya planta de producción se ubica en la Provincia Constitucional del Callao. A través de esta compañía es que se ha iniciado el desarrollo y exportación de la pulpa de tuna congelada.

De acuerdo con los valores analizados en el portal de Veritrade (2018); el contacto comercial se inició con el envío de pequeñas cantidades o muestras con el fin de que el cliente pueda probar y analizar el producto para finalmente en el año 2015 realizar los primeros envíos de contenedores de pulpa de tuna congelada al mercado de Estados Unidos.

Con estos datos estadísticos es posible determinar que, si bien existe un potencial desarrollo en la exportación de pulpa de tuna congelada al mercado de Estados Unidos, éste aún se encuentra en una fase inicial. 


\subsection{Análisis de la pulpa de tuna congelada en el mercado estadounidense}

\subsubsection{Características del mercado estadounidense}

Para describir el perfil del consumidor norteamericano nos debemos enfocar en cuatro factores que influyen en la tendencia de consumo y estos son: demográfico, económico, estilo de vida y tecnológico. A continuación, se detallará cada uno de ellos:

- Factor demográfico : Estados Unidos cuenta con una población de 327 millones de habitantes, siendo el tercer país más poblado del mundo, donde la media es de 37 años. La conformación de la población es bastante diversa, siendo el $77 \%$ de origen europeo, el $17 \%$ de raíces hispanas, $13 \%$ afroamericanos y 5\% asiáticos. Se proyecta que para el 2050 se incremente la población de origen hispano, pasando a ser el 30\% del total (United States Census Bureau, 2017).

- $\quad$ Factor económico: la economía del país norteamericano se está recuperando de una crisis de los años 2008-2009 debido a la burbuja hipotecaria. A raíz de esta situación, el consumidor americano tuvo que optimizar el beneficio ante la reducción del poder adquisitivo, siendo las compras más racionales. Es decir, se han vuelto consumidores conscientes y con menor tendencia a tener deudas. Asimismo, indicar que, buscan invertir en productos que le aseguren una mejor vejez; por tal motivo se interesan en adquirir vitaminas, suplementos alimenticios, cosméticos antienvejecimiento, etc. (Santander Trade Portal, 2018).

- Factor estilo de vida: este es un factor clave, ya que las personas toman mayor conciencia de la importancia de llevar una vida saludable. 
Un estudio realizado por Euromonitor (2017) acerca de los diferentes estilos de vida de acuerdo con el tipo de consumidor revela que, sin importar la categoría de clasificación, la buena alimentación y nutrición es un elemento primordial dentro de la vida cotidiana. Ya sea desde consumiendo vitaminas o suplementos, no añadiendo sal o azúcar, leyendo las etiquetas nutricionales o buscando organizaciones que los guíen con respecto al consumo saludable.

Por otro lado, es preciso indicar que el consumidor norteamericano está dispuesto a probar productos novedosos y de sabores regionales, ya que éstos les otorgan una mayor variedad al momento de elegir un alimento. La exigencia al decidir por un producto será valorada por la calidad de este, más no por el precio teniendo en cuenta que debe ser novedoso, amigable con el medio ambiente, entre otros atributos (Promperú, 2015).

- $\quad$ Factor Tecnológico: Debido a que el día a día de los estadounidenses transcurre de una forma muy rápida, éstos buscan opciones que se acoplen a su velocidad, no dejando de lado la calidad de lo que desean adquirir. Por tal razón, las ventas por internet y aplicaciones móviles se han incrementado ya que esta forma de compra les garantiza el consumo instantáneo (Promperú, 2015).

\subsubsection{Acuerdo de Promoción Comercial Perú-Estados Unidos}

Durante muchos años nuestro país gozó de los beneficios unilaterales que nos brindaba el ATPDEA1, sin embargo, con el fin de contar con una mayor apertura comercial se

\footnotetext{
${ }^{1}$ ATPDEA: Ley de Promoción Comercial y Erradicación de la Droga, fue promulgada el 06 de agosto de 2002 y estuvo vigente hasta diciembre de 2010. Dicha ley tuvo como antecedente el ATPA, Ley de Preferencias Arancelarias Andina, la misma que fue promulgada el 4 de diciembre de 1991. Cabe mencionar que al igual que al Perú, se otorgaban preferencias arancelarias a Bolivia, Colombia y Ecuador; como parte de la política americana para combatir la producción de narcóticos y el narcotráfico mediante el otorgamiento de beneficios comerciales para ayudar a los países a diversificar y fortalecer industrias legítimas. Las preferencias otorgadas en su momento por el ATPA y el ATPDEA sólo abarcaban un grupo limitado de partidas arancelarias, y se otorgaban por un plazo determinado, ello hacía que este mecanismo unilateral no constituyera una plataforma interesante para las inversiones a largo plazo.
} 
dieron inicio a las negociaciones con el gobierno de Estados Unidos para establecer un acuerdo bilateral. Es así como el 12 de abril de 2006 se firmó el Acuerdo de Promoción Comercial Perú-EE. UU (también llamado Tratado de Libre Comercio o TLC), el cual entró en vigor a partir del 01 de febrero de 2009 y se estableció una zona de libre comercio2 entre ambos países.

La integración comercial de nuestro país con Estados Unidos a través de este Acuerdo de Promoción Comercial consolidó la política de apertura comercial peruana, iniciada en los noventa, así como el fortalecimiento de las relaciones comerciales con Estados Unidos, que para ese momento era nuestro principal socio comercial. Es importante resaltar que para la puesta en vigencia de dicho tratado fue necesario llevar a cabo una reestructuración total que permita adecuar y sobre todo alinear procesos operativos que aseguren el cumplimiento de los nuevos estándares regulatorios estipulados por el gobierno de Estados Unidos.

El hecho de establecer un Tratado de Libre Comercio conlleva a que ambos países se encuentren en un plano de igualdad respecto a las competencias comerciales de tal manera que ambas naciones se beneficien.

De acuerdo con el portal Acuerdos Comerciales del Perú (2011), se pueden definir los siguientes objetivos del Acuerdo de Promoción Comercial entre Perú y Estados Unidos.

- Garantiza el acceso preferencial permanente de las exportaciones peruanas a la economía más grande del mundo.

- Atrae flujos de inversión privada nacional y extranjera, propiciando el desarrollo de economías de escala, un mayor grado de especialización económica y una mayor eficiencia en la asignación de los factores productivos.

\footnotetext{
${ }^{2}$ Zona de Libre Comercio: espacio por donde circulan libremente las mercaderías, sin pagar arancel y sin restricciones
} 
- Refuerza la estabilidad de la política económica y de las instituciones, así como mejora la clasificación de riesgo del Perú, lo que contribuye a rebajar el costo del crédito y a consolidar la estabilidad del mercado de capitales.

- Reduce la vulnerabilidad de la economía a crisis financieras externas e incrementa la estabilidad de nuestros indicadores macroeconómicos, al estrechar vínculos con las tendencias de una de las economías más estables del mundo.

\subsubsection{Operadores de Comercio Exterior}

En el mundo del comercio exterior confluirá más de un actor que brindará los servicios para llevar a cabo la logística de un determinado proceso (exportación, importación, etc). Dichos operadores deben estar acreditados por la Superintendencia Nacional de Aduanas y Administración Aduanera (SUNAT).

De acuerdo con la definición de Roberto Zagal, quienes conforman los operadores de comercio exterior son los despachadores de aduana (dueños o consignatarios, agentes de carga, despachadores oficiales y concesionarios postales), transportista internacional, agencia de carga y almacenes aduaneros (2008, p.85)

- Dueño o consignatario: es la persona natural o jurídica a cuyo nombre se encuentra manifestada la mercadería o que la adquiere por endoso del documento de transporte (Zagal, 2009, p. 253).

- Transportista Internacional: es la persona encargada del traslado de la mercancía de un territorio aduanero a otro. Asimismo, deberá emitir según la modalidad, el conocimiento de embarque, carta porte o guía aérea, y por medio de éste recibe una remuneración llamado flete (Acuerdos Comerciales, 2013).

- Agencia de carga: De acuerdo con el artículo 2 de la Ley General de Aduanas del 2010, se trata de "persona que puede realizar y recibir embarques, 
consolidar, y desconsolidar mercancías, actuar como operador de transporte multimodal sujetándose a las leyes de la materia y emitir documentos propios de su actividad, tales como conocimientos de embarque, carta de porte aéreo, carta de porte terrestre, certificados de recepción y similares".

- Almacenes aduaneros: Son recintos que almacenan carga por un determinado periodo de tiempo; éste puede administrado por la autoridad aduanera, el sector público o privado. SUNAT los define como "local destinado a la custodia temporal de las mercancías cuya administración puede estar a cargo de la autoridad aduanera, de otras dependencias públicas o de personas naturales o jurídicas, entendiéndose como tales a los depósitos temporales y depósitos aduaneros".

\subsubsection{Exportaciones peruanas de pulpa de tuna congelada a Estados Unidos}

Actualmente, Estados Unidos es el principal destino de exportación de la pulpa de tuna congelada. De acuerdo con las estadísticas que podemos encontrar en el portal de investigación de mercados, Veritrade (2018); los envíos de la pulpa de tuna congelada hacia el país norteamericano han mostrado una tendencia positiva tanto en términos de valor FOB (US\$) como peso neto expresado en kilos.

Tabla 8: Perú: exportaciones pulpa de tuna congelada al mercado de Estados Unidos periodo 2014-2017.

\begin{tabular}{|l|c|c|c|c|}
\hline \multicolumn{5}{|c|}{ Perú : exportaciones de pulpa de tuna congelada a USA } \\
\hline \multicolumn{5}{|c|}{ Período $\mathbf{2 0 1 4 - 2 0 1 7}$} \\
\hline FOB (US\$) & $\mathbf{2 0 1 4}$ & $\mathbf{2 0 1 5}$ & $\mathbf{2 0 1 6}$ & $\mathbf{2 0 1 7}$ \\
\hline Peso neto (kg) & 61.54 & $32,040.52$ & $83,747.00$ & $262,459.00$ \\
\hline Precio prom. (US\$) & 0.75 & 1.74 & 1.94 & 1.96 \\
\hline
\end{tabular}

Adaptado de Veritrade, 2018 


\subsection{Medidas para la exportación}

\subsubsection{Medidas arancelarias}

Las medidas arancelarias pueden ser definidas como aquellas "restricciones al comercio externo de un país, mediante tasas a la exportación e importación de bienes o servicios por parte de un país o una zona económica" (Economipedia, 2015).

Desde el punto de vista de la exportación; a través de las medidas arancelarias el país puede recaudar mayores impuestos. Por otro lado, desde la perspectiva de la importación un país pretende defender su producción nacional frente a la competencia externa.

En el marco del Acuerdo de Promoción Comercial Perú-EE. UU. que entró en vigor el 01 de febrero del 2009, se mantiene el acceso permanente con arancel cero para todos los productos incluidos en la Ley de Promoción Comercial y Erradicación de la Droga (SIICEX, 2015).

Para que un producto se beneficie de las preferencias arancelarias asignadas por el APC Perú-EE. UU., este debe ser originario de los países signatarios del mismo, para lo cual debe cumplir con los criterios de calificación de origen indicados en dicho Acuerdo y presentar el Certificado de Origen o Declaración de Origen de ser necesario (SIICEX, 2015).

De acuerdo con el arancel versión 2017, la pulpa de tuna congelada se encuentra comprendida en la partida general 2008.99.90.00 (Arancel de Aduanas, 2017, p.60). 


\begin{tabular}{|r|l|c|}
\hline Código & \multicolumn{1}{|c|}{ Designación de la mercadería } & A/V \\
\hline 20.08 & $\begin{array}{l}\text { Frutas u otros frutos y demás partes } \\
\text { comestibles de plantas, preparados o } \\
\text { conservados de otro modo, incluso con } \\
\text { adición de azúcar u otro edulcorante }\end{array}$ & 6 \\
\hline 2008.99 .20 .00 & Pas demayas & 6 \\
\hline 2008.99 .30 .00 & Mangos & 6 \\
\hline $\mathbf{2 0 0 8 . 9 9 . 9 0 . 0 0}$ & Los demás & 6 \\
\hline
\end{tabular}

Figura 11. Clasificación arancelaria de la pulpa de tuna congelada. Adaptado de Arancel de Aduanas 2017, por SUNAT, 2017

Si bien es cierto que en el Arancel 2017 se detalla Ad Valorem de 6\%, gracias al Acuerdo de Promoción Comercial entre Perú y Estados Unidos, dicha partida se encuentra liberada al 100\% de Ad Valorem.

\subsubsection{Medidas no arancelarias}

Las regulaciones no arancelarias son medidas establecidas por los gobiernos para controlar el flujo de mercancías entre los países, ya sea para proteger la planta productiva y las economías nacionales, o para preservar los bienes de cada país, en lo que respecta a medio ambiente, proteger la salud, sanidad animal y vegetal, o para asegurar a los consumidores la buena calidad de las mercancías que están adquiriendo, o darles a conocer las características de estas. Por su naturaleza, estas regulaciones resultan más difíciles de conocer, interpretar y cumplir, lo que ocasiona que en muchos casos no sean tan transparentes, ya que se originan en varias fuentes y, al igual que los aranceles, pueden ser modificadas en tiempos relativamente cortos (SIICEX, 2015).

\subsubsection{Requisitos sanitarios para la exportación de productos agroindustriales}

De acuerdo con la Resolución Jefatural N0162-2017-MINAGRI-SENASA, emitida el 07 de diciembre de 2017 (Resolución Jefatural N0162-2017-MINAGRI-SENASA: art. 
$3^{\circ}$ ), se aprueba la lista de mercancías agrarias reguladas por el SENASA y el Glosario de Términos que se les aplica estableciendo categorías de riesgo para Sanidad Animal y Vegetal.

La pulpa de tuna al ser un producto que se exporta en presentación congelada y habiendo pasado por un proceso de pulpeado y pasteurización; es considerada dentro del grupo de riesgo 1 ante el Servicio Nacional de Sanidad (SENASA). Este grupo se refiere a aquellos productos y subproductos de origen animal y vegetal que han sido sometidos a un proceso que elimina la posibilidad de vehiculizar agentes patógenos o plagas de importancia cuarentenaria. El SENASA se reserva la facultad de inspeccionarlos cuando lo considere necesario, no estando sujetos a control obligatorio. Los procesos considerados para productos de origen vegetal en el aspecto fitosanitario Son:

Tabla 9: Perú: procesos considerados para productos de origen vegetal en el aspecto fitosanitario

\begin{tabular}{|l|l|}
\hline Apertizado & Malteado \\
\hline Blanqueo (fibra textil) & Pasteurización \\
\hline Carbonizado & Preservación \\
\hline Cocción & Presurización \\
\hline Confitado & Procesamiento con métodos múltiples \\
\hline Congelamiento & Pulpaje \\
\hline Encurtido & Reducción a puré (licuado) \\
\hline Esterilización & Salado \\
\hline Expandio o inflado & Sublimado \\
\hline Extracción (por calor y química) & Sulfitado \\
\hline Extrusión & Teñido \\
\hline Fermentación & Tostado \\
\hline Liofilizado & \\
\hline
\end{tabular}

Adaptado de Resolución Jefatural № 0162-2017 MINAGRI-SENASA, por diario "El Peruano", 2017 
La pulpa de tuna congelada al estar dentro del grupo de riesgo 1 no necesita la emisión de certificado sanitario.

Por otro lado, al ser un producto agroindustrial no existen requisitos sanitarios obligatorios por parte de la Dirección General de Salud Ambiental (DIGESA), sin embargo, se puede solicitar a dicha entidad el Certificado de Libre Comercialización (SIICEX, 2015).

\subsubsection{Ley contra el bioterrorismo}

A raíz del atentado terrorista del 11 de setiembre de 2001 que sufrió Estados Unidos; el gobierno norteamericano decidió implementar una serie de medidas con el objetivo de evitar y eliminar cualquier tipo de amenaza que atente contra el país y su población. Ante ello, se instauró la Ley contra el Bioterrorismo (MINCETUR, 2003).

Entendemos por Bioterrorismo a todo aquel empelo criminal de microorganismos patógenos, toxinas o sustancias dañinas contra la población con el propósito de generar enfermedad, muerte, pánico y terror. Es también introducir en un país, material biológico con agentes fitopatógenos, enfermedades cuarentenarias, insumos químicos o cualquier otro tipo de material que atente contra la vida y la salud de las personas (MINCETUR, 2003).

La Ley contra el Bioterrorismo se resume en cuatro principales disposiciones:

\section{- Registro de instalaciones alimenticias}

Exige que todas las instalaciones alimenticias, nacionales e internacionales, que manufacturan, procesan, empacan y almacenan alimentos que van a ser consumidos en Estados Unidos deben registrarse en la FDA. El registro de instalaciones fue habilitado el 16 de octubre y comenzó a ser exigido a partir del 12 de diciembre de 2003, a través 
de la notificación previa. La norma final sobre el Registro de Instalaciones Alimenticias se publicó el 28 se septiembre de 2005.

Dentro del registro para un establecimiento de alimentos se solicita los datos de un agente, quien es la persona de contacto requerida por la Food and Drug Administration en Estados Unidos. Esta persona deberá residir en Estados Unidos y no necesariamente tiene que estar vinculada a las actividades productivas o comerciales de la instalación (Promperú, 2008).

\section{- Notificación previa de partidas de alimentos importados}

Exige que cada vez que se embarquen alimentos a Estados Unidos estos deben notificarse a la FDA, previo al arribo del embarque. La notificación previa es exigida para alimentos que van a ser usados o distribuidos en Estados Unidos, incluyendo los regalos, muestras comerciales, muestras para asegurar la calidad y para control de calidad, alimentos que transitan a través de Estados Unidos hacia otro país, así como alimentos enviados por correo. Esta normativa fue puesta en vigencia desde el 12 de diciembre de 2003. La notificación previa debe ser recibida y confirmada electrónicamente en un plazo no mayor a 15 días antes del arribo del embarque y no menor de:

2 horas antes del arribo vía terrestre

4 horas antes del arribo por aérea o férrea

$>8$ horas antes del arribo vía marítima

\section{- Establecimiento y mantenimiento de registros}

Las personas que fabrican procesan, envasan, distribuyen, reciben, almacenan o importan alimentos estarán obligados a crear y mantener los registros que la Food and Drug Administration estime necesarios para identificar las fuentes previas de 
abastecimiento y los receptores posteriores de estos alimentos, es decir, de donde vienen y quienes lo reciben.

\section{- Detención administrativa}

Se autoriza a la Food and Drug Administration retener administrativamente alimentos, si la agencia tiene pruebas o información creíble de que dichos alimentos representan una amenaza de consecuencias negativas graves para la salud o muerte de personas o animales.

\subsubsection{Ley de Modernización de la inocuidad de los alimentos} (FSMA)

La Ley de Modernización de Inocuidad de los Alimentos (FSMA) fue firmada por el ex presidente de EE. UU., Barack Obama el 4 de enero del 2011. Es la reforma más profunda de las leyes de seguridad alimentaria en más de 70 años en dicho país y tiene como objetivo garantizar que el suministro de alimentos de Estados Unidos sea seguro cambiando el enfoque reactivo por el preventivo (Promperú, 2017).

En el marco de esta Ley se han promulgado 7 nuevas normas finales, que son:

- Estándares para el cultivo, cosecha, empaque y almacenamiento/mantenimiento de productos frescos agrícolas.

Aplica para productos frescos y busca regular la calidad microbiológica del agua, ingreso al campo de animales salvajes y domésticos, uso de estiércol fresco, compost y fertilizantes y capacitación de trabajadores en salud e higiene.

\section{- Controles preventivos para alimentos de consumo humano.}

Aplica para las plantas procesadoras de alimentos para consumo humano. En este punto se implementa un sistema de inocuidad de alimentos que incluya el análisis de los peligros y controles preventivos basados en riesgos (HARPC), control de la cadena de 
suministros y actualización y aclaración de la aplicación de Buenas Prácticas de Manufactura Actuales (CGMP)

- Controles Preventivos para alimentos de consumo animal.

Aplica para las plantas procesadoras de alimentos para consumo animal en el cual se Implementa un sistema de inocuidad de alimentos que incluya el análisis de los peligros y controles preventivos basados en riesgos (HARPC), control de la cadena de suministros y definición de la aplicación de Buenas Prácticas de Manufactura Actuales (CGMP).

\section{- Programa de Verificación de Abastecedores Extranjeros (PVPE).}

Aplica para empresas importadoras. En esta normal se verifica que los proveedores extranjeros estén produciendo alimentos de una forma adecuada, que los proveedores cumplan con los controles preventivos o las regulaciones de seguridad de productos según corresponda y asegurar que los alimentos del proveedor no estén adulterados y mal etiquetados respecto a la rotulación de alérgeno.

- Transporte Higiénico de alimentos para consumo humano y animal. Aplica para transportistas de alimentos para consumo humano y animal dentro de EE. UU. Busca prevenir prácticas que creen riesgos de inocuidad alimentaria durante el transporte dentro de EE. UU., tales como no refrigerar de manera apropiada el alimento, limpieza inadecuada de vehículos entre cargas y no proteger de manera adecuada al mismo.

- Acreditación de terceros para auditorias en inocuidad alimentaria. Aplica para organismos de certificación de terceros. Se establece un programa voluntario para la acreditación de organismos de certificación de terceros, también conocidos como auditores, para llevar a cabo auditorías de seguridad alimentaria y 
expedir certificaciones de instalaciones extranjeras de alimentos de consumo humano y animal.

- Estrategias de mitigación centradas en la protección de alimentos contra la adulteración intencional.

Aplica para empresas que elaboran alimentos procesados para consumo humano en el cual se establece que las instalaciones de EE. UU. y extranjeras aborden los procesos vulnerables en sus operaciones a fin de prevenir los actos sobre el suministro de alimentos destinados a provocar daños a la población a gran escala. La norma exige a las empresas alimentarias más grandes que tengan un plan de defensa de los alimentos por escrito que aborde las vulnerabilidades significativas en una operación con alimentos.

\subsubsection{Requisitos sobre colorantes, aditivos, acidificación y control de permiso emergencia}

Colorante: un colorante es cualquier tinte, pigmento o sustancia que, al ser aplicado a un alimento, medicamento, cosmético o al cuerpo humano les da color. La FDA es la encargada de autorizar el uso de los colorantes nuevos antes de ser utilizada en el alimento a comercializarse en los EE. UU. Asimismo, este organismo establece en qué alimentos se puede usar y las cantidades máximas permitidas y la identificación que debe de estar en el etiquetado del producto (SIICEX, 2015).

Aditivos alimentarios: un aditivo alimentario es toda sustancia que, sin constituir por sí misma un alimento ni poseer valor nutritivo, se agrega intencionadamente a los alimentos y bebidas en cantidades mínimas con objetivo de modificar sus caracteres organolépticos o facilitar o mejorar su proceso de elaboración o conservación (CODEX STAN 1071981). La FDA ha definido una lista de las sustancias aprobadas para utilizarse como aditivos directos e indirectos (SIICEX, 2015). 
Productos de Baja Acidez o Acidificados: la FDA reconoce como productos de baja acidez, aquellos productos que son tratados con calor, con un $\mathrm{pH}$ mayor a 4,6, una actividad del agua mayor 0,85 y que se venden en envases herméticos. Los productos acidificados son aquellos a los que se en su elaboración se le agrega algún ácido para bajar el $\mathrm{pH}$ a 4,6 o a menos y con actividad de agua > 0,85. Las regulaciones de la FDA establecen que todos los procesadores de productos de baja acidez o acidificados que se quieran comercializar deben registrar sus plantas para obtener el FCE (Food Canning Establishment Number). Adicionalmente, para cada producto que se desee comercializar, es necesario obtener un registro SID (Submission Identifier).

\subsubsection{Buenas Prácticas de Manufactura (BPM)}

Establecen condiciones básicas y actividades necesarias para mantener un ambiente higiénico durante la producción, manipulación y provisión, con el fin de preparar alimentos inocuos para el consumo humano. El Código de Regulaciones Federales de EE. UU., Título 21, Parte 110 (21 CFR 110) establece las disposiciones para la implementación de las BPM que incluye, las persona, los edificios e instalación, la producción y procesos de control y el almacenaje y distribución de los mismos (SIICEX, 2015).

\subsubsection{Sistema de análisis de peligro y puntos críticos de control (HACCP)}

Permite identificar los peligros específicos (biológicos, químicos y físicos) y las medidas para su control con el fin de garantizar la inocuidad de los alimentos. Este instrumento sirve para evaluar los peligros y establecer sistemas de control que se centran en la prevención en lugar de basarse en el ensayo del producto final. Actualmente, el Sistema de HACCP es obligatorio sólo para productos hidrobiológicos y para jugos que se fabrican y comercializan en los EE. UU., siéndolo para los jugos de 
frutas. Sin embargo, en el Perú su aplicación es obligatoria para productos destinados al mercado nacional e internacional de acuerdo con la "Norma Sanitaria para la aplicación del Sistema HACCP en la fabricación de Alimentos y Bebidas” según Resolución Ministerial N 449- 2006/MINSA (SIICEX, 2015).

\subsubsection{Envase y embalaje}

El envasado deberá hacerse en condiciones higiénicas tales que impidan la contaminación del producto. Los materiales utilizados en el interior del envase deben ser nuevos, estar limpios y con las características requeridas, evitando así cualquier daño externo o interno al producto. Se permite el uso de materiales, en particular papel o sellos, con indicaciones comerciales siempre y cuando estén impresos o etiquetados con tinta o pegamento no tóxico. Se emplea el Codificador Universal de Productos (UPC o código de barras), el cual consiste en un código de dígitos que presentan información específica del productor (empacador o embarcador) y del producto (tipo de producto, tamaño de empaque, variedad, cantidad, etc.) que funcionan para el control rápido de inventario.

Los materiales de empaque y embalaje se seleccionan en base a las necesidades del producto, método de empaque, método de pre-enfriamiento, resistencia, costo, disponibilidad, especificaciones del comprador, tarifas de flete y consideraciones ambientales.

Cuando se utiliza embalajes de madera, estas deberán contar con un sello que certifique que ha recibido tratamiento térmico o de fumigación contra plagas mediante Bromuro de Metilo. Este sello es otorgado por SENASA en base al cumplimiento de las Normas Internacional para Medidas Fitosanitarias - NIMF (o International Standards for Phytosanitary Measures - ISPM), específicamente de la NIMF 15 "Directrices para 
reglamentar el embalaje de madera utilizado en el comercio internacional” (o ISPM 15 "Guidelines for Regulating Wood Packaging Material in International Trade"). Dicha norma describe las medidas fitosanitarias para reducir el riesgo de introducción y/o dispersión de plagas cuarentenarias relacionadas con el embalaje de madera (incluida la madera de estiba), fabricado de madera en bruto de coníferas y no coníferas, utilizado en el comercio internacional (SIICEX, 2015).

\subsubsection{Etiquetado}

Todo producto alimenticio que se comercialice en los EE.UU. debe llevar un rótulo que cumpla la normativa que se encuentran en el Código de Regulaciones Federales, Título 21, Parte 101 "Food Labeling” (21 CFR 101). De lo contrario, las autoridades prohibirán la entrada del producto en su territorio. Los requisitos referentes al etiquetado de productos agroindustriales procesados se encuentran estipulados en las normativas del rotulado General, rotulado nutricional y el código de barras (SIICEX, 2015).

\subsubsection{Transporte}

Dependiendo del tipo de producto, existen requisitos específicos que describen cómo debe realizarse el transporte físico de determinados productos importados por EE.UU. Para lo cual se tiene que considerar la temperatura, humedad relativa, composición atmosférica y almacenamiento en frío (SIICEX, 2015).

De acuerdo con el Mg. Juan Carlos Ganoza Aleman, funcionario de Promperú, dada la naturaleza de la pulpa de tuna congelada esta es considerada dentro de la cadena logística como un producto perecible en la que agentes como la temperatura, la humedad o la presión son determinantes para que el alimento comience su deterioro. 
Para asegurar la preservación de los alimentos perecibles congelados, estos se deben mantener a temperatura entre $-18^{\circ} \mathrm{C}$ y $-40^{\circ}$ Celsius.

\subsection{Principales ferias internacionales de alimentos}

La participación en ferias internacionales es una herramienta de gran relevancia ya que resultan ser un escaparate publicitario. Dentro del rubro alimentos son diversas las ferias que se llevan a cabo alrededor del mundo. A continuación, se detallan las principales:

- Summer Fancy Food: se inició en 1955 y se realiza todos los años en Estados Unidos en la ciudad de New York. Este año se realizará desde el 30 de junio hasta el 02 de julio de 2018 (Specialty Food Association Inc, 2018).

- Winter Fancy Food: al igual que Summer Fancy, ésta es considerada una de las más grandes ferias de alimentos y bebidas en Estados Unidos, se lleva a cabo en San Francisco y se realiza en los primeros meses de cada año (Specialty Food Association Inc, 2018).

- Anuga: se realiza en Colonia, Alemania. Cuenta con 10 ferias especializadas en un mismo lugar, se lleva a cabo cada dos años. La próxima edición será el 2019 del 05 al 09 de octubre (Anuga, 2018).

- Sial: esta feria se lleva a cabo en París, Francia. Cuenta con 19 sectores de productos y se realiza cada dos años. Del 21 al 25 de octubre de este año se desarrollará este mega evento (Sial, 2018).

- The American Frozen Food Institute (AFFI): esta feria está avocada principalmente a productos congelados, se desarrolla todos los años en Las Vegas, Estados Unidos (American Frozen Food Institute, 2018). 


\section{CAPÍTULO II - METODOLOGÍA DE INVESTIGACIÓN}

\subsection{Planteamiento de la investigación :}

\subsubsection{Propósito de la investigación}

El propósito del presente trabajo de investigación es realizar un análisis situacional de las exportaciones de pulpa de tuna congelada peruana al mercado de Estados Unidos durante el periodo 2013-2017.

\subsubsection{Objetivo general de la investigación}

El objetivo general de nuestra investigación es conocer las razones por las cuales las exportaciones de pulpa de tuna congelada peruana al mercado de Estados Unidos no han sido significativas a pesar de que la coyuntura nacional se ha mostrado favorable para el sector agroexportador durante el periodo 2013-2017.

\subsubsection{Objetivos especificos de la investigación}

- Comprender la percepción de las asociaciones productoras de tuna y exportadoras de pulpa de tuna congelada respecto al apoyo por parte de las entidades públicas para el fortalecimiento de sus capacidades de gestión.

- Determinar las medidas no arancelarias que han dificultado la exportación de la pulpa de tuna congelada peruana al mercado de Estados Unidos.

- Precisar si las empresas exportadoras de pulpa de tuna congelada conocen y participan de las principales ferias de alimentos a nivel mundial. 


\subsubsection{Preguntas de la investigación}

\section{Pregunta principal}

¿Por qué las exportaciones de pulpa de tuna congelada peruana al mercado de Estados Unidos no han sido significativas a pesar de que la coyuntura nacional se ha mostrado favorable para el sector agroexportador durante el periodo 2013-2017?

\section{Preguntas secundarias}

- ¿Se percibe como insuficiente el apoyo por parte de las entidades públicas para el fortalecimiento de las capacidades de gestión de las asociaciones productoras de tuna y exportadoras de pulpa de tuna congelada?

- ¿Existen medidas no arancelarias que afectan la exportación de pulpa de tuna congelada peruana a Estados Unidos?

- ¿Las empresas exportadoras de pulpa de tuna congelada peruana desconocen o no participan de las principales ferias de alimentos a nivel mundial?

\subsubsection{Justificación}

$\mathrm{Al}$ analizar el panorama actual de las exportaciones de pulpa de tuna congelada hacia el mercado de Estados Unidos, es posible observar un desempeño positivo y con una tendencia de crecimiento.

La tuna es un fruto que, a comparación de otros cuenta con la principal ventaja de no requerir grandes cantidades de agua. Tal como lo indicó Hans Dreyer, director de la División de Producción y Protección Vegetal de la FAO: “el cambio climático y la creciente amenaza de las sequías son razones importantes para promover el humilde cactus al estatus de cultivo esencial en muchas áreas" (Freshplaza, 2017). Con esta recopilación de datos es que se busca realizar un análisis situacional de las exportaciones de pulpa de tuna congelada peruana al mercado de Estados Unidos durante el periodo 2013-2017. 


\subsubsection{Hipótesis de la investigación}

De acuerdo con Hernández Sampieri, R., Fernández Collado C., Baptista Lucio, M. (2014), "las hipótesis son las guías de una investigación o estudio. Las hipótesis indican lo que tratamos de probar y se definen como explicaciones tentativas del fenómeno investigado. Se derivan de la teoría existente y deben formularse a manera de proposiciones" (p.104).

\section{HIPÓTESIS GENERAL}

Existen barreras que han impedido el fortalecimiento e incremento de las exportaciones de pulpa de tuna congelada peruana al mercado de Estados Unidos durante el periodo 2013-2017.

\section{HIPÓTESIS ESPECÍFICAS}

- Las asociaciones productoras de tuna y exportadoras de pulpa de tuna congelada perciben como insuficiente el apoyo por parte de las entidades públicas para el fortalecimiento de sus capacidades de gestión.

- Las medidas no arancelarias afectan la exportación de pulpa de tuna congelada a Estados Unidos.

- Las empresas exportadoras de pulpa de tuna congelada peruana desconocen y no participan de las principales ferias de alimentos a nivel mundial.

\subsection{Metodología de investigación}

El presente trabajo de investigación responde al enfoque cualitativo, ya que tiene como propósito realizar un análisis situacional de las exportaciones de pulpa de tuna congelada peruana al mercado de Estados Unidos durante el periodo 2013-2017 de manera clara, objetiva y precisa. 
De acuerdo con Hernández Sampieri, R., Fernández Collado C., Baptista Lucio, M. (2014), "la investigación cualitativa se enfoca en comprender los fenómenos explorándolos desde la perspectiva de los participantes en un ambiente natural y en relación con su contexto" (p.358).

\section{FUENTES PRIMARIAS}

Para la elaboración del presente trabajo se tomó como punto de partida el Plan Estratégico Nacional Exportador 2025 (PENX), teniendo en cuenta los cuatro pilares en que se basa, estos son los siguientes:

Pilar 1: internacionalización de la empresa y diversificación de mercados

Pilar 2: oferta exportable, diversificada, competitiva y sostenible

Pilar 3: facilitación del comercio exterior y eficiencia en la cadena logística

Pilar 4: generación de capacidades para la internacionalización y consolidación de una cultura exportadora.

Por último, se realizaron entrevistas a expertos en temas de promoción y desarrollo de exportación como Promperú y la Oficina Comercial del Perú en Los Ángeles; con ésta última se validó la información sobre los obstáculos arancelarios y no arancelarios para la exportación de pulpa de tuna congelada hacia Estados Unidos.

\section{FUENTES SECUNDARIAS}

Se utilizaron diversos documentos, artículos, informes de organismos internacionales, entre otros. A continuación, se hace una breve descripción de los principales entes usados para este trabajo:

VERITRADE. Base de datos sobre la exportación de tuna congelada durante el periodo 2014-2016. 
FAO. Boletín de servicio agrícola. Informe sobre la utilización agroindustrial del nopal

PROMPERU. Oportunidades comerciales en Estados Unidos. Informe sobre los aspectos más relevantes para la exportación al país norteamericano. CENSUS. Organismo encargado de brindar estadísticas a nivel poblacional de Estados Unidos

EUROMONITOR. Consumer types. Estudio sobre la clasificación y tipos de consumidores que existen en Estados Unidos.

CODEX ALIMENTARIUS. Código de prácticas de higiene para alimentos poco ácidos. Documento que brinda a detalle sobre los lineamientos que se debe seguir y/o tener en cuenta para alimentos de baja acidez (como la tuna).

\section{MUESTRA O PARTICIPANTES}

Tal como lo señala Hernández Sampieri, R., Fernández Collado C., Baptista Lucio, M. (2014) una muestra en el proceso cualitativo es un "grupo de personas, eventos, sucesos, comunidades, etc., sobre el cual se habrán de colectar los datos, sin que necesariamente sea estadísticamente representativo del universo o población que se estudia" (p.384).

Luego de comprender el enfoque a aplicar, se procederá a seleccionar de la manera más oportuna la muestra de la investigación.

Antes de iniciar nuestro primer acercamiento al trabajo de campo, se decidió escoger la muestra de expertos a entrevistar.

Como parte de nuestra muestra o participantes, estos han sido clasificados por sector público (Promperú, Ministerio de Agricultura), sector privado (empresas exportadoras de productos frutícolas en presentación congelada), expertos en el tema de comercio exterior e internacionalización de mercados y agricultores/acopiadores de tuna. Se 
podrá encontrar mayor detalle sobre la organización de nuestra muestra o participantes en el punto 3.3. el cual se refiere al diseño o abordaje principal.

\subsection{Diseño o abordaje principal}

\subsubsection{Segmentos}

Se procedió a segmentar a nuestros actores en 4 grupos, los cuales se señalan a continuación.

- Grupo de actores 1: sector público representado por Promperú y el Ministerio de Agricultura (MINAGRI)

- Grupo de actores 2: sector privado representado por empresas exportadoras de productos frutícolas en presentación congelada.

- Grupo de actores 3: especialistas relacionados

- Grupo de actores 4: productores y/o acopiadores de tuna

\subsubsection{Categorias}

Se procedió a clasificar nuestras preguntas en 3 categorías basadas en el PENX 2025, los cuales se señalan a continuación.

- Categoría 1: Análisis situacional de exportación y oferta exportable

- Categoría 2: Logística de entrada y salida

- Categoría 3: Requisitos técnicos y de calidad

\subsubsection{Instrumento de investigación}

De acuerdo con Hernández Sampieri, R., Fernández Collado C., Baptista Lucio, M. (2014), el instrumento de recolección de los datos en el proceso cualitativo es el propio 
investigador, quien a través de diversos instrumentos como las entrevistas o grupos de enfoque logra recoger los datos para luego ser analizados (p.397).

Para el desarrollo de nuestra tesis se tomó la decisión de elegir las entrevistas como técnica de recolección de datos y levantamiento de información primaria. A través de las entrevistas que realizaremos a la muestra previamente definida en el punto anterior se podrá conocer con mayor profundidad el contexto en el que se encuentra la situación de la exportación de pulpa de tuna congelada hacia el mercado de Estados Unidos y de esta manera poder validar nuestras hipótesis. Asimismo, será posible recolectar información que no se encontraba considerada dentro de nuestra investigación y que nos puede brindar un mayor panorama en el desarrollo de nuestra tesis.

\subsubsection{Identificación de la estructura de la entrevista}

En cuanto a la estructura de la entrevista, estas se dividen en estructuradas, semiestructuradas y no estructuradas o abiertas (Hernández Sampieri et al., 2014, p.403).

Las entrevistas semiestructuradas se basan en una guía de asuntos o preguntas y el entrevistador tiene la libertad de introducir preguntas adicionales para precisar conceptos u obtener más información (Hernández Sampieri et al., 2014, p.403).

\subsubsection{Guía de preguntas}

Las guías de preguntas de las entrevistas semiestructuradas se encuentran en el Anexo de la presente tesis.

\subsection{Procedimientos}

El procedimiento utilizado para nuestra investigación consignó los siguientes pasos: 
- El primer paso para llevar a cabo nuestras entrevistas fue determinar cuáles serían las categorías que comprenderían nuestra bitácora de investigación. Una vez definidas estas categorías en base al PENX 2025 nos enfocamos en determinar nuestros segmentos que serían especialistas relacionados al tema.

- Estos especialistas fueron seleccionados de acuerdo con el tipo de información que necesitábamos recabar con el fin de obtener la mayor información posible para el tema de nuestra investigación y se procedió a contactarlos y fijar una fecha de entrevista.

- Una vez agendadas las entrevistas con los especialistas de cada segmento se pudo obtener datos para comparar la información presentada en el primer capítulo. Podemos concluir que no todos los entrevistados aceptaron que los grabemos por vídeo o audio. Asimismo, algunos entrevistados por temas de tiempo y agenda nos ayudaron con las preguntas de nuestra entrevista a través del correo electrónico, lo cual permitió la evidencia por este medio.

- Las preguntas formuladas en el diseño de la entrevista han sido semiestructuradas. Cabe resaltar que, en medio de las entrevistas personales se dio paso a otras preguntas que se formularon en el momento y que nos brindaron mayores detalles para la validación de nuestra hipótesis.

- Una vez logradas todas las entrevistas de manera presencial y virtual; se procedió a llenar nuestra bitácora con el fin de formular las respectivas conclusiones por cada categoría y sector. 


\section{CAPÍTULO III - ANÁLISIS DE DATOS Y RESULTADOS}

En el presente capítulo se detalla la información obtenida a través de las entrevistas realizadas a los cuatro grupos de actores mencionados en el capítulo anterior. Para estructurar las entrevistas se tomó en consideración las cuatro dimensiones de los pilares del PENX.

\subsection{Grupo de actores 1: sector público}

Para la elaboración de la presente categoría se tomó en consideración a personal que labora en PROMPERU y Ministerio de Agricultura (MINAGRI), quienes aportaron información especializada basada en estadísticas y su experiencia en el rubro.

\section{A.1. Categoría 1: Análisis situacional de exportación y oferta exportable}

Señalan que las exportaciones no tradicionales han ido en aumento, destacándose el envío de frutas. El 2017 se logró el mayor crecimiento de los últimos cinco años en este tipo de envíos, siendo el sector agro el segundo generador de divisas lo que refleja que hay una mayor demanda de productos peruanos en el exterior con valor agregado.

En cuanto al comportamiento del mercado respecto a la exportación de pulpa de tuna congelada, no se tiene un panorama aún definido, sin embargo, se prevé un crecimiento ya que se están desarrollando cada vez más productos, como por ejemplo bebidas a base de tuna. Asimismo, hicieron referencia que la industrialización de esta fruta sería la mejor opción para la exportación, porque evita controles sanitarios (reducción de costo y tiempo). 
Si de promocionar el producto se trata, señalan que la participación en ferias y misiones comerciales son de vital importancia para poner en vitrina los productos a exportar, eso sí, tener en cuenta que para negociar se debe contemplar el tema de la oferta exportable, porque no se obtendrían resultados en ofrecer un producto y no tener la capacidad de poder atender el pedido.

En cuanto al papel que desempeñan las OCEX indicaron que una de las principales funciones es el desarrollo de investigación de mercado, pero no sólo a través de reportes; sino por el contrario son el nexo entre el importador y exportador, para ello realizan un seguimiento con el fin de que pueda concretarse el negocio y/o resuelvan cualquier inquietud de las partes involucradas.

Por otro lado, aludieron que hasta el momento no se ha dado una alianza entre el sector público y privado para la difusión de este producto. Para que ello se lleve a cabo se requiere de una participación como gremio y es algo que aún no se ha realizado o lo que se ha logrado hasta el momento ha sido incipiente.

También mencionaron, que, si bien la tuna cuenta con beneficios nutricionales, aún hay criterios que faltan trabajar con el fin de que sea considerada dentro de la categoría de "Super Fruits", tales como la oferta exportable o su funcionalidad.

Asimismo, refirieron que si bien es cierto el principal exportador de esta fruta es México, un importador consideraría al Perú como alternativa por su gran sabor, mayor grado Brix y color (requisito importante para determinar la venta).

Con respecto a las zonas de producción de tuna, señalaron que el departamento de Ayacucho es el que tiene la mayor productividad, no obstante, en esta zona se cultiva de forma silvestre; en cambio en Lima (Huarochirí), los agricultores han optado por tener otro tipo de cuidados con el propósito de obtener una mejor calidad de fruta. Referente a la situación actual de las zonas productoras de tuna, indicaron que no cuentan con la 
adecuada tecnología, además que los productos usados para evitar plagas son bastante fuertes; es decir no hay un control integrado de manejo de tuna a nivel nacional. Indicaron que juntamente con APROTYC (Asociación de Productores de Tuna y Cochinilla) se han realizado desarrollos tecnológicos, capacitaciones en temas agrícolas, así como de comercialización y exportación; y además se ha buscado financiamiento para hacer una planta procesadora de frutas y ácido carmínico.

Esperan que para los próximos tres años puedan contar con maquinaria que ayude a mejorar la postcosecha, así como también optimizar la obtención de cochinilla, ya que hoy en día el proceso no es el adecuado y por el contrario perjudica la salud del agricultor.

Por último, consideran que para desarrollar el cultivo de tuna de manera más competitiva se debe trabajar en varios puntos como el control de plagas y enfermedades, las altitudes de producción, mejoramiento de postcosecha, temas de fertilización y debe desarrollarse un estudio real de los parámetros de cantidad de agua que necesita este cultivo.

\section{A.2. Categoría 3: Requisitos técnicos y de calidad}

Referente a si consideran las barreras arancelarias y no arancelarias verdaderos obstáculos para desarrollar el potencial exportador de pulpa de tuna congelada, hay opiniones dividas, para algunos esto sí representa una traba y para otros, ayuda a proteger la vida humana porque hay un mayor control a través de ellas.

Por otro lado, señalaron que las empresas exportadoras peruanas de productos agroindustriales de gran envergadura tienen conocimiento de los requisitos de exportación; sin embargo, ello no exime que en alguna oportunidad su carga haya sido retenida en destino. 
Si de apoyo se trata, hicieron énfasis en que el gobierno, en la medida de lo posible, hace todo su esfuerzo para dar a conocer todos los requisitos o medidas técnicas para la exportación a través de entidades como PROMPERU, dicha institución lleva a cabo charlas de diversas índoles relacionadas al comercio exterior; éstas se dan de forma presencial o si es virtual, es por medio de correos electrónicos o vía streaming.

Consideran que a raíz de temas políticos (terrorismo), las leyes norteamericanas se han tornado más estrictas, sobre todo en el tema alimentario que ha sido uno de los puntos con mayor relevancia, llevando a cabo un control preventivo, además de la trazabilidad del producto que va desde el exportador hasta el importador.

\subsection{Grupo de actores 2: sector privado}

Para la presente categoría, colaboradores de la empresa Selva Industrial S.A. aportaron información especializada para entender la coyuntura de la presente sección aplicada a nuestra investigación.

\section{B.1. Categoría 1: Análisis situacional de exportación y oferta exportable}

El desempeño de las exportaciones de productos agroindustriales durante los últimos cinco años ha sido positivo a pesar de las inestabilidades políticas y económicas que ha sufrido nuestro país. Debido al óptimo desempeño de las exportaciones de productos agroindustriales se puede observar que paulatinamente el envío de pulpa de tuna congelada se ha ido incrementado desde el año 2015 hasta la fecha. Esta información, definitivamente, nos permite concluir que existe un gran potencial para la producción y exportación de la pulpa de tuna congelada. Además de ser un producto novedoso, es también importante recalcar que la materia prima (tuna) a comparación de otros frutos no requiere grandes cantidades de agua por lo que su cultivo es mucho más atractivo desde la perspectiva financiera. Los principales puntos en que se debe trabajar para 
desarrollar el sector de la tuna de manera más competitiva en la principal zona de producción es el tema de la oferta. Tal como comentó el Jefe de Logística Agrícola de la empresa Selva Industrial S.A., en el caso que la demanda por la pulpa de tuna congelada aumentara ve poco probable que esta pueda ser atendida satisfactoriamente por un tema de déficit de volumen de la materia prima.

De otro lado, no es posible determinar si se ha establecido un tipo de alianza entre el sector público y privado para la difusión de la tuna y sus propiedades. Se considera que aún se debe desarrollar un trabajo conjunto entre el Ministerio de Agricultura (MINAGRI) y Promperú con el fin de difundir las propiedades y beneficios de la tuna. Por su lado, la empresa Selva Industrial S.A. actualmente asiste a dos ferias internacionales. La primera es Anuga en Alemania y la segunda es Sial París en Francia. Definitivamente concuerdan que es de vital importancia la participación en ferias y misiones comerciales con el fin de difundir el portafolio de productos que la empresa ofrece así también como mantener una imagen vigente ante el mercado internacional y fortalecer relaciones comerciales.

\section{B.2. Categoría 2: Logística de entrada y salida}

Actualmente, la empresa exportadora Selva Industrial S.A. compra el abastecimiento de la materia prima (tuna) directamente con un agricultor que también cumple la función de acopiador. La temporada de la tuna es relativamente corta, inicia a mediados de diciembre y dura hasta marzo o principios de abril. El principal inconveniente que se presenta durante el traslado de la fruta hacia la planta de procesamiento es el estado de la carretera que lleva a la Panamericana Sur, la cual no se encuentra en buen estado y eso conlleva a que la fruta se dañe durante el traslado. Como medida de solución, la empresa vio conveniente utilizar jabas de plástico para evitar fuertes golpes entre los 
frutos de la tuna y llegue en las mejores condiciones a la planta procesadora ubicada en Callao.

La pulpa de tuna congelada es exportada principalmente a los siguientes puertos de Estados Unidos: Seattle, Longbeach, Port Everglades y New York. La exportación se realiza en contenedores reefer de 40 " a una temperatura de $-18^{\circ} \mathrm{C}$. Dado que el principal y por el momento único destino de la pulpa de tuna congelada es Estados Unidos, hay ciertos parámetros de calidad que se deben tomar en cuenta. Uno de ellos es el nivel de ph de la fruta, el cual no debe exceder el valor de 4,6. En caso un producto sea exportador con un nivel de ph mayor al límite, este no podrá ingresar al país norteamericano y será retenido ante la Food and Drug Administration (FDA). Asimismo, las autoridades norteamericanas solicitan que el exportador envíe como mínimo 72 horas antes que la nave arribe a puerto de origen un documento conocido como "ISF 10+2 form" en el cual se detalla información relativa al embarque. En caso el exportador no cumpla con dicha medida se genera una multa de US\$5,000.

De acuerdo con la información recibida por parte de nuestros entrevistados, los factores más críticos para la exportación de la pulpa de tuna congelada se basan en el factor fisicoquímico del producto expresado en términos de brix, color y ph; y por el lado logístico se tiene la disponibilidad de espacios en las naves. Cuando es temporada alta (meses de enero y febrero) donde frutas como el mango, maracuyá aumentan en volumen de exportación; la disponibilidad de espacios se vuelve una dificultad y se corre el riesgo de no cumplir con los plazos de entrega que indica el comprador.

\section{B.3. Categoría 3: requisitos técnicos y de calidad}

En general, se puede concluir que las empresas exportadoras peruanas de productos agroindustriales tienen conocimiento técnico acerca de las normativas que tiene el gobierno de Estados Unidos. Asimismo, estas empresas cuentan con el apoyo de 
entidades del Estado como Promperú y privadas como la Asociación de Exportadores (ADEX) o la Cámara de Comercio de Lima (CCL), entidades que brindan charlas informativas acerca del tema como "Miércoles del Exportador" que se organiza todos los días miércoles en las instalaciones de Promperú.

Respecto a las barreras arancelarias y no arancelarias que tiene la exportación de la pulpa de tuna congelada se puede concluir que no son considerados como obstáculos. Por ejemplo en tema de arancel, gracias al Acuerdo de Promoción Comercial USAPerú, la partida de la pulpa de tuna paga un arancel de $0 \%$ Ad valorem y por el lado de las barreras no arancelaria; si bien es cierto el tema del nivel de ph no mayor a 4.6 puede retrasar el embarque no es un tema que impida el envío, ya que corresponde al exportador el poder adecuarse a dichos reglamentos técnicos de calidad y así asegurar la inocuidad del producto final llevando de igual manera un buen control en los puntos críticos como la pasteurización y filtrado. Es importante resaltar que todo el proceso productivo sigue los lineamientos del Codex Alimentarius, los reglamentos de BPM (Buenas Prácticas de Manufactura), HACCP e Inocuidad alimentaria.

Por otro lado, se concluye que las certificaciones son muy importantes hoy en día y pueden llegar a ser determinantes para consolidar una venta.

\subsection{Grupo de actores 3: sector experto}

Formaron parte de este sector, ex funcionarios de Promperú y el Ministerio de Agricultura (MINAGRI), así como también una consultora especializada en requisitos técnicos de ingreso a Estados Unidos.

\section{C.1. Categoría 1: Análisis situacional de exportación y oferta exportable}

Destacan que las exportaciones no tradicionales han presentado un crecimiento. Esto se debe a la consolidación de empresas, políticas de internacionalización de nuevos 
productos, capacitaciones, presencia de cooperativas y asociaciones en las principales ferias, entre otros factores.

Respecto al comportamiento de la exportación de pulpa de tuna congelada, señalan que la exportación en dicha presentación va en aumento, sin embargo, el valor en comparación a otras frutas aún es mínimo. Hoy en día, sólo existe una empresa exportadora que ofrece la pulpa de tuna en presentación congelada y por ello resaltan que sería conveniente que otras compañías puedan seguir el mismo ejemplo. No obstante, muchas veces estos temas de diversificación de productos, por temas de organización no se llegan a ejecutar. Definitivamente, se concuerda que la industrialización de la tuna sería la forma óptima para su exportación.

Destacaron, que la participación en ferias y misiones comerciales tiene mucha importancia ya que ayuda a la difusión del producto. A nivel local, esto ha servido para cerrar negocios con las principales cadenas de supermercados; asimismo, subrayaron que contar con oferta exportable es primordial.

Referente a las Oficinas Comercial del Perú en el Exterior (OCEX), distinguieron que el papel que desarrollan es de suma relevancia, ya que son el hilo conductor entre el exportador e importador con el fin de establecer vínculos estratégicos. Dentro de sus funciones se encuentra el análisis de mercado, evaluación de empresas, facilitación del comercio exterior, entre otros.

En cuanto al establecimiento de alianzas entre el sector público y privado, indican que no existe algo de tal naturaleza; eso no se ha podido concretar por falta de presupuesto, desorganización, falta de interés por parte del municipio o agricultores. Esto se tendría que acordar con la ayuda de Ministerios como el Ministerio de Agricultura (MINAGRI) o el Ministerio del Ambiente. 
Asimismo, se mencionó que para que la tuna sea considerada dentro del grupo de "Super Fruits", se debe conformar un gremio y/o asociación con la finalidad de tener mayor notoriedad y exigir que esta fruta sea incluida dentro de dicho grupo.

Igualmente, consideran que un importador de pulpa de tuna congelada optaría por comprar tuna peruana en vez de la mexicana, a pesar de que es el principal proveedor a nivel mundial, por un tema de diferenciación ya que cuenta con más de una variedad. Lo que concierne a las zonas de mayor producción de tuna destacan los departamentos de Ayacucho y Ancash, en dichos lugares crece de forma silvestre, en contraste al departamento de Lima (Huarochirí) la producción de esta fruta es más especializada. A pesar de que, la tuna en comparación a otras frutas no requiere de mucha agua para su cultivo, en la actualidad la falta de este curso está generando problemas en las zonas de producción, por lo que necesitan con urgencia implementar un reservorio para hacer más eficiente el sembrío de tuna.

Con lo que respecta a las asociaciones, la que destaca es APROTYC, con ellos se ha concretado diversos planes de estudio como el tratamiento postcosecha, planes de negocio para la difusión y compra de fruta, así como la organización de ferias en el mismo poblado, todo ello gracias al programa Sierra y Selva Exportadora. La expectativa de producción de dicho sector para los próximos 3 años es de crecimiento en la zona de Huarochirí, detallaron que la cosecha del fruto se da entre 1 a 2 años, y si se trata de plantaciones jóvenes las cosechas serán fructíferas siempre y cuando no interfiera el fenómeno del niño.

Por último, consideran que para que las zonas productoras de tuna se desarrollen de manera más competitiva se debe implementar un sistema de riego adecuado, debe haber un control de plagas (mosca de la fruta) y realizar ferias permanentemente; éste último ya no se da por falta de presupuesto y organización entre el estado y el municipio. 


\section{C.2. Categoría 3: Requisitos técnicos y de calidad}

En cuanto a las barreras arancelarias y no arancelarias, todos los entrevistados concuerdan que no son obstáculo para el potencial desarrollo de pulpa de tuna congelada. La exportación en esta presentación (congelada) no requiere algún tipo de autorización por parte del Servicio Nacional de Sanidad Agraria (SENASA) ya que, al ser procesada, no tiene problemas de plagas, pero debido a su alta acidez es necesario el uso de aditivos para regular el nivel de ph. Es preciso indicar que la implementación de la normativa sanitaria estadounidense puede ser una limitante principalmente para las PYMES, por su alto costo.

Las incidencias por detención de productos por temas técnicos han decrecido, este es un claro ejemplo de que las empresas han ido adquiriendo experiencia e información con la finalidad de no tener problemas relacionados a ello, ya que tiene un costo muy alto. Para que se haya podido llevar a cabo, han tenido que aunar esfuerzos tanto el sector público y privado con el fin de obtener información adecuada para minimizar errores.

Consideran que el Estado peruano, a través de entidades correspondientes, hace énfasis en la difusión de requisitos o medidas técnicas para la exportación de productos agroindustriales, uno de ellos es Promperú con su programa "Miércoles del exportador" en las diversas plataformas ya sea presencial o virtual. El mismo alcance tiene el Centro de Innovación Productiva y Transferencia Tecnológica (CITE) por medio de sus publicaciones y proyectos.

Con relación a la legislación norteamericana, los entrevistados afirmaron que antes del 2011, ya había normas que regulaban todo el tema de productos alimenticios, sin embargo, a partir del ataque terrorista, se implementaron nuevas leyes volviéndose todo mucho más estricto. Si bien es cierto, estas normas tienen un enfoque preventivo como 
el HACCP, hacen hincapié en la capacitación del personal, control de actividades de saneamiento, control de la cadena de suministro, alérgenos, entre otros.

Por último, recalcaron que el APC (Acuerdo de Promoción Comercial entre Perú y Estados Unidos) favorece en temas arancelarios, acceso a tecnología, entre otros; sin embargo, las normas técnicas son de aplicación general independientemente que haya un acuerdo comercial o no con un determinado país. Éstas han sido verificadas por la OMC, el reto está en que las empresas revisen y cumplan con lo que la legislación del país le exige para ingresar productos agroindustriales.

\subsection{Grupo de actores 4: Sector productores y acopiadores}

Para el presente sector, agricultores de la Asociación de Productores de Tuna y Cochinilla (APROTYC) y agricultores/acopiadores particulares aportaron información especializada para entender la coyuntura de la presente sección aplicada a nuestra investigación

\section{D.1. Categoría 1: Análisis situacional de exportación}

Para esta categoría se concluye que el factor determinante para que el agricultor opte por el cultivo de la tuna o cochinilla es el precio y la demanda actual. En muchos casos, los agricultores destinan dos áreas separadas para cultivar en una zona tuna y en otra la cochinilla porque no se puede obtener ambos productos de una sola penca.

El precio de la tuna depende de la demanda y estacionalidad. La temporada de la tuna está comprendida entre los meses de diciembre a abril aproximadamente. Durante estos meses el precio de la tuna es estable, pero a partir de finales de abril a mayo el precio puede incrementarse por estar fuera de temporada.

Las principales zonas de producción se concentran en Huarochirí en los poblados de Yana, Cuculí-Villa Pampilla, Matará, Chatacancha y Calahuaya. 
En torno a la pregunta si los agricultores conocen alguna entidad ya sea del Estado o privada que fomente la difusión del cultivo y beneficios de la tuna se pudo concluir que hay dos puntos de vista. Por un lado, podemos concluir que el Estado, a través del programa "Sierra y Selva Exportadora" ha brindado apoyo a APROTYC como sociedad conformada por un grupo de agricultores, sin embargo, esta ayuda solo está enfocada en desarrollar planes de negocio postcosecha (fomentar el comercio de la tuna en presentación fresca). Por otro lado, respecto al apoyo técnico ambos coinciden en que algún momento el Estado a través del Instituto Nacional de Innovación Agraria (INIA) ha enviado, en algunas oportunidades, ingenieros agrónomos, pero no se llegó a concretar ningún plan por falta de presupuesto, desconocimiento del área y desorganización de los mismos agricultores asociados,

En ambos casos se coincide que la demanda por la tuna tiene una tendencia de crecimiento. Si mencionamos variedades, la tuna roja es la que ha aumentado en cantidad de hectáreas. Tal como lo indicaron, hace unos años atrás se ha empezado a cultivar en las zonas altas de Huarochirí la tuna roja y se ha obtenido mejores resultados; una fruta de mayor calibre y sabor más dulce.

\section{D.2. Categoría 2: Logística de entrada y salida}

A pesar de los buenos resultados en volumen de cultivo, se hizo hincapié que el principal inconveniente que se tiene en el traslado de la tuna hacia las plantas de producción y zonas de ventas es la carretera que ayuda a salir a la Panamericana Sur. Como no se encuentra en buen estado y es estrecha solo se permite el tránsito de camiones con capacidad entre 10-15 toneladas de producto.

\section{D.3. Categoría 3: Requisitos técnicos y de calidad}

Actualmente no se recibe apoyo técnico por parte del Estado o entidad privada. Los mismos agricultores se encargan de ver el tema de compra de fertilizantes y abonos. Sin 
embargo, no cierran las puertas a cualquier entidad que desee brindar apoyo técnico para sacar adelante el cultivo y producción de la tuna. 


\section{CAPÍTULO IV - DISCUSIÓN DE RESULTADOS}

Para el desarrollo del siguiente capítulo, se ha tomado en consideración toda la información obtenida en cada categoría desarrollada a través de las entrevistas realizadas. La finalidad de este proceso es poder realizar un análisis situacional que permita conocer las razones por las cuales las exportaciones de pulpa de tuna congelada peruana al mercado de Estados Unidos no han sido significativas a pesar de que la coyuntura nacional se ha mostrado favorable para el sector agroexportador durante el período 2013-2017.

\subsection{Hallazgos de la investigación}

\section{A. Discusión de resultados de la primera categoría: análisis situacional de exportación}

En cuanto al análisis situacional de las exportaciones, las agroexportaciones han mostrado un crecimiento sostenido durante los últimos cinco años, siendo el año 2017 el de mejor desempeño. En torno al fruto de la tuna, la principal zona productora es Ayacucho, sin embargo, el cultivo se da de manera silvestre en comparación al departamento de Lima; específicamente en la zona de Huarochirí (poblados de Yana, Cuculí-Villa Pampilla, Matará, Chatacancha y Calahuaya) en donde se lleva un mejor manejo de cultivo. Para los próximos tres años, se cuenta con una expectativa de crecimiento en la zona de Huarochirí, siempre y cuando no interfiera el Fenómeno del Niño. La relevancia de la oferta exportable es un punto clave para el desarrollo y fortalecimiento de la industria de tuna y derivados, ya que si no contamos con la suficiente materia prima no será posible atender y cumplir con los volúmenes requeridos por el mercado internacional. Es importante recalcar que el cultivo de tuna al no 
requerir de grandes cantidades de agua es un negocio atractivo para los agricultores desde la perspectiva financiera.

Si bien es cierto que la pulpa de tuna congelada se está utilizando para la elaboración de nuevos productos como bebidas, aún no se ha desarrollado lo suficiente y se hace hincapié en que es de vital importancia la industrialización de la misma ya que evita controles sanitarios significando un ahorro tanto en costos como tiempo. Actualmente, existe solo una empresa peruana exportadora de pulpa de tuna congelada, la cual inició los envíos de este producto en el año 2015 mostrando un crecimiento sostenido hasta la fecha. Por otro lado, las OCEX juegan un rol importante para impulsar las exportaciones peruanas ya que son el nexo entre el importador y exportador brindando un respaldo. Asimismo, la participación en ferias internacionales es clave para promover e impulsar no solo el portafolio de productos sino también la imagen que desea proyectar la empresa agroexportadora. Por último, mencionar que se han realizado intentos por parte del Estado y empresas productoras y procesadoras para llevar a cabo una serie de propuestas que enlacen y promuevan el aspecto técnico y comercial. No obstante, no se ha logrado concretar un trabajo conjunto por temas de presupuesto, organización e intereses de ambas partes.

\section{B. Discusión de resultados de la segunda categoría: logística de entrada y salida}

El abastecimiento de materia prima (tuna) se realiza desde Huarochirí, se hace a través de un acopiador que a la vez desempeña el papel de agricultor. Debido al mal estado de la carretera que lleva a la panamericana sur, se ha optado por el uso de jabas de plástico, con la finalidad de que la fruta no se maltrate.

El principal medio de transporte para la exportación de pulpa de tuna congelada es vía marítima, en contenedores reefer de 40" y el destino por excelencia es Estados Unidos. 
El factor más crítico dentro de la cadena logística es la disponibilidad de espacios en el barco, sobre todo cuando es temporada alta de exportación de frutas como el mango y maracuyá (meses de enero y febrero).

C. Discusión de resultados de la tercera categoría: requisitos técnicos y de calidad

Tanto el estado (Promperú) como el sector privado (ADEX, CCL) han venido

realizando una labor ardua para dar a conocer los requisitos que se necesitan para la exportación de productos agroindustriales. A través de sus distintos programas y/o plataformas es que hacen llegar información y así evitar en lo posible que empresas peruanas sean sancionadas por estos temas. La implementación de la normativa sanitaria que solicita el mercado estadounidense podría ser considerada una limitante para las algunas empresas, en su mayoría PYMES, por su alto costo.

Al contar con un acuerdo de promoción comercial con Estados Unidos, el arancel para este producto es $0 \%$ Ad valorem, esto por el lado de las barreras arancelarias. Con respecto a las barreras no arancelarias se tiene que tomar en cuenta principalmente que el nivel de ph no sea mayor a 4.6. Es importante indicar que todo proceso productivo debe seguir los lineamientos del Codex Alimentarius, los reglamentos de BPM (Buenas Prácticas de Manufactura), HACCP e Inocuidad alimentaria. Por lo antes mencionado, se afirma que las barreras arancelarias y no arancelarias no representan obstáculos para la exportación de pulpa de tuna congelada.

\subsection{Barreras de investigación}

Las principales barreras de investigación que hemos encontrado en el presente trabajo fueron las siguientes: (i) los pocos contactos en el sector público y experto y (ii) el 
acotado tiempo asignado. Las barreras mencionadas conllevaron a que no se puedan concretar más entrevistas con la finalidad de profundizar el tema.

En cuanto al sector público, no logramos contactar a un funcionario especializado en promoción y desarrollo del sector agroindustrial. Para el caso del sector experto, se intentó contactar a un ex funcionario del Ministerio de Agricultura y Riego y a una especialista en normas técnicas a través de correos y llamadas, pero hasta la culminación del presente trabajo, no se ha recibido respuesta alguna.

Por último, consideramos que, para dar un diagnóstico con un mayor alcance hubiera sido necesario conocer la realidad de los agricultores de tuna de otros departamentos como Ayacucho, Cusco y no sólo Lima; pero por falta de tiempo no se pudo concretar las visitas y entrevistas

\subsection{Brechas de investigación}

Consideramos que la principal brecha para realizar esta investigación fue la escaza información que existe con relación a la tuna a nivel región. Hasta el momento, en nuestro país no se ha desarrollado ningún estudio y/o paper con respecto a esta fruta en comparación de otras tales como el maracuyá, mango, arándanos, etc.

Si bien es cierto que, hay investigaciones sobre el desarrollo y la industrialización de tuna en otros países, como por ejemplo México, es necesario conocer con mayor detalle el escenario actual peruano referente a la producción e industrialización de tuna con el fin de incrementar el rendimiento de los cultivos, así también como la diversificación de productos (presentaciones como tuna en IQF, jugos, jaleas, entre otros).

Esperamos que esta investigación sea el punto de partida, para que se fomente el interés en torno a la tuna y su potencial exportador. 


\section{CAPÍTULO V - CONCLUSIONES Y RECOMENDACIONES}

\subsection{CONCLUSIONES}

Con el presente estudio hemos alcanzado el objetivo principal y la validación de nuestra hipótesis general que permite confirmar y conocer la existencia de barreras que han impedido el fortalecimiento e incremento de las exportaciones de pulpa de tuna congelada peruana a Estados Unidos durante el periodo 2013-2017.

Respecto a nuestra primera hipótesis específica, esta ha sido validada, ya que los entrevistados manifestaron que, si bien es cierto, el Estado ha brindado apoyo técnico y de gestión comercial tanto a las asociaciones productoras de tuna y empresas exportadoras de pulpa de tuna, este ha sido percibido como insuficiente porque no se llegó a implementar en su totalidad por factores como desorganización, falta de intereses en común y presupuesto.

La segunda hipótesis específica ha sido rechazada, ya que las barreras no arancelarias no suponen un obstáculo para la exportación de pulpa de tuna congelada peruana hacia Estados Unidos. La adición del ácido cítrico, ascórbico o málico no significa el impedimento para la exportación; ya que de acuerdo con el Codex Alimentarius y las Buenas Prácticas de Manufactura (BPM), está permitido el uso de estos aditivos en cantidades que el exportador crea más conveniente.

La tercera hipótesis específica ha sido rechazada, esto debido a que las empresas entrevistadas indicaron que conocen las principales ferias del rubro de alimentos a nivel mundial y participan en algunas de ellas como Anuga (Alemania), Sial (Francia) y AFFI (Estados Unidos). Por otro lado, todos los sectores concluyeron que la participación en 
ferias internacionales es de gran importancia, ya que permite dar a conocer los productos y brindar una imagen de confianza para los potenciales compradores.

La tuna es un fruto característico de la sierra peruana, cuya principal ventaja de cultivo es el bajo consumo de agua, en comparación de otros como los arándanos, palta, naranja, etc. Asimismo, hay que indicar que la cantidad de hectáreas sembradas se han incrementado en los últimos cinco años, esto a raíz del crecimiento de la demanda tanto a nivel local como del exterior.

Las oficinas comerciales en el exterior cumplen una función vital como nexo entre un potencial importador y exportador. A través de ellos se desarrollan planes de negocio, inteligencia comercial y también brindan respaldo comercial para ambas partes.

De acuerdo con los especialistas entrevistados, podemos concluir que la forma óptima y conveniente de exportación de la tuna es la industrialización, ya que evita controles fitosanitarios, ahorrando así tiempo y dinero. Por otro lado, a través de este proceso productivo se generan mayores puestos de trabajo y el precio de venta es mayor a que si se exportara en presentación fresco.

\subsection{RECOMENDACIONES}

Realizar estudios sobre la tuna a nivel productivo (altitudes, consumo de agua, uso de fertilizantes), este será el punto de partida para mejorar la calidad de la fruta, así como su rendimiento con miras a aumentar la oferta exportable. Por otro lado, el apoyo técnico por parte de especialistas a los agricultores respecto a la postcosecha será de gran ayuda.

Plantear campañas promocionales aunando el esfuerzo del sector público y privado con el fin de poner en vitrina a la tuna y sus derivados, de manera que se fomente un mayor cultivo y a la vez estandaricen los procesos para que el producto sea competitivo en los mercados de destino. 
Diseñar un plan conjunto entre el programa "Sierra y Selva Exportadora" y la Asociación de Productores de Tuna y Cochinilla (APROTYC) con el fin de capacitar y desarrollar planes de negocios con miras a la exportación. 


\section{BIBLIOGRAFÍA}

Acuerdos Comerciales del Perú (2011). TLC Perú-EE. UU. Lima: Ministerio de Comercio Exterior $\quad$ y $\quad$ Turismo. Recuperado de http://www.acuerdoscomerciales.gob.pe/index.php?option=com_content\&view=categor y\&layout=blog\&id=56\&Itemid=79 [Consulta: 08 de febrero de 2018].

América Economía (2018). Agroexportaciones de Perú sumaron US\$ 6.255M en 2017 y llegaron $\quad$ a 149 países. Lima. Recuperado de https://www.americaeconomia.com/negocios-industrias/agroexportaciones-de-perusumaron-us6255m-en-2017-y-1legaron-149-paises [Consulta: 18 de mayo de 2018] American Frozen Food Institute - AFFI (2018). AFFI. Estados Unidos. Recuperado de http://www.affi.org/ [Consulta: 07 de junio de 2018]

Anuga (2018). Anuga. Alemania. Recuperado de http://www.anuga.com/ [Consulta: 07 de junio de 2018].

Baptista, P., Fernández, C., Hernández, R. (2014). Metodología de la Investigación. (6a. ed.). México: McGraw-Hill Interamericana.Centro de Comercio Internacional (ITC). (s.f.). Medidas No Arancelarias. Suiza: ITC. Recuperado de http://www.intracen.org/itc/analisis-mercados/medidas-no-arancelarias/ [Consulta: 11 de abril de 2018].

Economipedia (2015). Barreras Arancelarias. España: Economipedia. Recuperado de http://economipedia.com/definiciones/barreras-arancelarias.html [Consulta: 15 de febrero de 2018].

El Peruano. (07 de diciembre de 2017). Aprueban Lista de Mercancías Agrarias reguladas por el SENASA y el Glosario de Términos que se les aplica, establecen 5 Categorías de Riesgo para Sanidad Animal y Vegetal y dictan otras disposiciones. 
Recuperado de http://busquedas.elperuano.pe/normaslegales/aprueban-lista-demercancias-agrarias-reguladas-por-el-senas-resolucion-jefatural-no-0162-2017-minagrisenasa-1596609-1/ [Consulta: 01 de marzo de 2018].

Fideicomiso para la Construcción y Operación de la Central de Abasto de la Ciudad de México (FICEDA). (2016). Es Temporada de Tuna. México D.F.: FICEDA. Recuperado de http://ficeda.com.mx/ficeda/app/webroot/_archivos/057\%20TEMPORADA\%20DE\%20 TUNA.pdf [Consulta: 25 de abril de 2018].

Martínez, H. (2012). Metodología de la investigación. México, D.F.: Cengage Learning. Passport Euromonitor. (2017). Euromonitor International. Obtenido de Consumer Typer: US. https://www.portal.euromonitor.com/portal/account/login\# [Consulta: 08 de enero de 2018].

Ministerio de Agricultura y Riego (MINAGRI) (2016). Serie de estadísticas de Producción Agrícola (SEPA). Lima: Minagri. Obtenido de http://www.minagri.gob.pe/portal/sistemas-de-informacion. [Consulta: 15 de marzo de 2018].

Ministerio de Agricultura y Riego (MINAGRI) (2017). Sistema de Abastecimiento y Precios (SISAP). Lima: Minagri. Obtenido de http://sistemas.minag.gob.pe/sisap/portal/ [Consulta: 28 de abril de 2018].

Ministerio de Comercio Exterior y Turismo (Mincetur). (2003). Ley de EE. UU. contra el Bioterrorismo. Lima: Mincetur. Recuperado de https://www.mincetur.gob.pe/wpcontent/uploads/documentos/comercio_exterior/Sites/Bioterrorismo/index.htm [Consulta: 08 de abril de 2018].

Organización de las Naciones Unidas para la Agricultura y la Alimentación (FAO). (2006). Utilización agroindustrial del nopal. Roma: FAO. Recuperado de http://www.fao.org/3/a-a0534s.pdf [Consulta: 10 de enero de 2018]. 
Pinto, J. (2000). Asignación y Determinación de Prioridades de Procesos Esenciales, con base en los Factores Críticos de Éxito. Recuperado de: https://ebookcentral.proquest.com/lib/upcsp/reader.action?docID=3164161\&ppg=1 [Consulta: 13 de enero de 2018].

Portal Frutícola. (2013). Una mirada regional al mercado de la tuna. Lima: Portal Frutícola. Recuperado de https://www.portalfruticola.com/noticias/2013/04/08/unamirada-regional-al-mercado-de-la-tuna/ [Consulta: 15 de enero de 2018].

Promperú (2017). Exportaciones Perú 2017. Lima. [ Presentación para la charla Miércoles del Exportador]. Lima: Promperú.Proyecto UE-PERU/PENX (s.f.). $A B C$ del Comercio Exterior Vol III. [Presentación del Ministerio de Comercio Exterior y Turismo]. Lima: Promperú. Recuperado de https://www.mincetur.gob.pe/wpcontent/uploads/documentos/comercio_exterior/Sites/ueperu/consultora/docs_taller/guia s/Guia_Practica_del_Exportador_1.pdf [Consulta: 05 de marzo de 2018].

Quintana Sánchez, N. (2015). Oportunidades Comerciales en EE. UU. [Presentación para la charla del Miércoles del Exportador]. Lima: Promperú. Recuperado de http://www.prompex.gob.pe/miercoles/Portal/MME/descargar.aspx? $\operatorname{archivo=66B5412D~}$ -9CED-4021-90AE-608A80E35232.PDF [Consulta: 11 de marzo de 2018].

Real Academia Española (RAE). (2017). Nopal. En Diccionario de la lengua española. $23^{\mathrm{a}}$ ed. http://dle.rae.es/?id=QbVcGeO_[Consulta: 10 de enero de 2018].

Santander Trade Portal (2018). Estados Unidos: llegar al consumidor. España: Santander. Recuperado de https://es.portal.santandertrade.com/analizarmercados/estados-unidos/llegar-al-consumidor [Consulta: 08 de febrero de 2018].

Sial (2018). Sial. Francia - París. Recuperado de https://www.sialparis.com/ [Consulta: 07 de junio de 2018]. 
Sistema Integrado de Información de Comercio Exterior (SIICEX). (s.f.). Tuna. Lima: SIICEX.

http://www.siicex.gob.pe/siicex/resources/fichaproducto/Tuna.pdf [Consulta: $10 \mathrm{de}$ enero de 2018].

Sistema Integrado de Información de Comercio Exterior (SIICEX). (2015). Guía de Requisitos de Acceso de Alimentos a los Estados Unidos. Lima: SIICEX. Recuperado de http://www.siicex.gob.pe/siicex/documentosportal/1025163015radB52B3.pdf [Consulta: 20 de abril de 2018].

Specialty Food Association Inc. (2018). Summer Fancy Food Show. Estados Unidos. Recuperado de https://www.specialtyfood.com/shows-events/summer-fancy-foodshow/ [Consulta: 07 de junio de 2018].

Superintendencia Nacional de Aduanas y de Administración Tributaria (SUNAT). (2017). Tratamiento Arancelario por subpartida nacional. Obtenido de http://www.aduanet.gob.pe/itarancel/arancelS01Alias. [Consulta: 16 de febrero de 2018].

United States Census Bureau. (2018). Population Clock. USA: United States Census Bureau. Recuperado de https://www.census.gov/ [Consulta: 11 de enero de 2018].

Veritrade. (2018). México - Exportaciones de tuna fresca en términos de valor FOB 2015-2017/ Partida 0810.90.99. [Fichero de Datos]. Obtenido de https://www.veritradecorp.com/ [Consulta: 23 de abril de 2018].

Veritrade. (2018). México - Exportaciones de pulpa de tuna aséptica en términos de valor FOB 2015-2017/ Partida 2007.99.99/2008.99.99. [Fichero de Datos]. Obtenido de https://www.veritradecorp.com/ [Consulta: 23 de abril de 2018]. 
Veritrade. (2018). Perú - Exportaciones de tuna fresca en términos de valor FCA (US\$)

2013-2017/ Partida 0810.90.90.00 [Fichero de Datos]. Obtenido de https://www.veritradecorp.com/ [Consulta: 23 de abril de 2018].

Veritrade. (2018). Perú - Exportaciones de tuna fresca en peso neto (kg)2013-2017/ Partida 0810.90.90.00 [Fichero de Datos]. Obtenido de https://www.veritradecorp.com/ [Consulta: 23 de abril de 2018].

Veritrade. (2018). Perú - Exportaciones de tuna fresca en precio promedio (US\$)20132017/ Partida 0810.90.90.00 [Fichero de Datos]. Obtenido de https://www.veritradecorp.com/ [Consulta: 23 de abril de 2018].

Veritrade. (2018). Perú - Exportaciones de pulpa de tuna congelada en términos de valor FOB (US\$)2014-2017/ Partida 2008.99.90.00 [Fichero de Datos]. Obtenido de https://www.veritradecorp.com/ [Consulta: 23 de abril de 2018].

Veritrade. (2018). Perú - Exportaciones de pulpa de tuna congelada en términos peso neto (kg)2014-2017/ Partida 2008.99.90.00 [Fichero de Datos]. Obtenido de https://www.veritradecorp.com/ [Consulta: 23 de abril de 2018].

Veritrade. (2018). Perú - Exportaciones de pulpa de tuna congelada en términos de precio promedio (US\$)2014-2017/ Partida 2008.99.90.00 [Fichero de Datos]. Obtenido de https://www.veritradecorp.com/ [Consulta: 23 de abril de 2018].

Veritrade. (2018). Perú - Exportaciones de pulpa de tuna congelada hacia Estados Unidos en términos de valor FOB, peso neto y precio promedio 2014-2017/ Partida 2008.99.90.00 [Fichero de Datos]. Obtenido de https://www.veritradecorp.com/ [Consulta: 23 de abril de 2018].

Yovera Aliaga, A. (2008). Requisitos para la Exportación de Alimentos a los EE. UU. [Presentación para la charla del Miércoles del Exportador]. Lima: Promperú. Recuperado 
http://www.prompex.gob.pe/Miercoles/Portal/MME/descargar.aspx? $\operatorname{archivo=0343E147~}$ -7BAE-4241-814D-614D4B83FF02.PDF [Consulta: 19 de abril de 2018].

Zagal, R. (2008) Operativa de Comercio Exterior y Regímenes Aduaneros. Lima. UNMSM.

Zagal, R. (2009) Operativa de Comercio Exterior y Regímenes Aduaneros. Lima. UNMSM. 


\section{ANEXOS}

\subsection{Cuestionario de la entrevista: sector público}

\begin{tabular}{|c|c|c|}
\hline $\mathbf{N}^{\circ}$ & Dimensiones & Actores grupo 1: sector público \\
\hline \multirow{14}{*}{1} & \multirow{14}{*}{$\begin{array}{l}\text { Análisis situacional de } \\
\text { exportación }\end{array}$} & $\begin{array}{l}\text { Preg 1: ¿Cómo ha observado la evolución de las exportaciones } \\
\text { de productos no tradicionales específicamente } \\
\text { agroexportaciones durante los últimos } 5 \text { años? }\end{array}$ \\
\hline & & $\begin{array}{l}\text { Preg 2: ¿Cómo ve el comportamiento del mercado respecto a la } \\
\text { exportación de pulpa de tuna congelada? ¿prevé un crecimiento? }\end{array}$ \\
\hline & & $\begin{array}{l}\text { Preg 3: ¿Se ha establecido algún tipo de alianza entre el sector } \\
\text { público y privado para la difusión de este producto? Si es sí } \\
\text { ¿Cuáles son? Si es no ¿Qué estrategias se podrían desarrollar } \\
\text { para promover la exportación de este producto? }\end{array}$ \\
\hline & & $\begin{array}{l}\text { Preg 4: Teniendo en cuenta los beneficios nutricionales de la } \\
\text { tuna ¿cuáles son los motivos por los que no está considerada } \\
\text { dentro de la categoría de Super Fruits? }\end{array}$ \\
\hline & & $\begin{array}{l}\text { Preg 5: Actualmente, ¿asisten a ferias internacionales? ¿Cuáles? } \\
\text { ¿considera la participación a ferias y misiones comerciales como } \\
\text { parte importante para la promoción de este producto? }\end{array}$ \\
\hline & & $\begin{array}{l}\text { Preg 6: ¿Por qué un importador de tuna congelada consideraría a } \\
\text { nuestro país como alternativa de proveedor teniendo en cuenta } \\
\text { que México es el principal productor y exportador de tuna? }\end{array}$ \\
\hline & & $\begin{array}{l}\text { Preg 7: ¿Qué papel desempeñan las OCEX’s? ¿Dentro de sus } \\
\text { funciones se encuentra el análisis de mercados? }\end{array}$ \\
\hline & & $\begin{array}{l}\text { Preg 8: Cuáles son las regiones productoras más importantes de } \\
\text { tuna? }\end{array}$ \\
\hline & & $\begin{array}{l}\text { Preg 9: ¿Cuáles son las expectativas de producción del sector de } \\
\text { la tuna para los próximos tres años? }\end{array}$ \\
\hline & & $\begin{array}{l}\text { Preg 10: ¿Cuál es la situación actual de las zonas productoras de } \\
\text { tuna? }\end{array}$ \\
\hline & & $\begin{array}{l}\text { Preg 11: ¿Existen asociaciones y/o cooperativas de productores } \\
\text { de tuna? }\end{array}$ \\
\hline & & $\begin{array}{l}\text { Preg 12: ¿Considera que existe potencial para la producción y } \\
\text { exportación de la tuna industrializada? ¿Qué ventajas tiene el } \\
\text { cultivo de esta fruta en comparación a otros? }\end{array}$ \\
\hline & & $\begin{array}{l}\text { Preg 13: En torno al fruto de la tuna, ¿qué objetivos se han } \\
\text { alcanzado a través de los programas que Sierra y Selva } \\
\text { Exportadora lleva a cabo (planes de negocio, promoción y } \\
\text { difusión, capacitaciones)? }\end{array}$ \\
\hline & & $\begin{array}{l}\text { Preg 14: ¿Cuáles considera son los principales temas en los que } \\
\text { se debe trabajar para desarrollar el sector de la tuna de manera } \\
\text { más competitiva en las principales zonas de producción? }\end{array}$ \\
\hline
\end{tabular}




\begin{tabular}{|c|c|c|}
\hline $\mathbf{N}^{\circ}$ & Dimensiones & Actores grupo 1: sector público \\
\hline \multirow{6}{*}{3} & \multirow{6}{*}{$\begin{array}{l}\text { Requisitos técnicos y } \\
\text { de calidad }\end{array}$} & $\begin{array}{l}\text { Preg 1: Según su experiencia, ¿cree usted que las barreras } \\
\text { arancelarias y no arancelarias son verdaderos obstáculos para } \\
\text { desarrollar el potencial exportador de la pulpa de tuna } \\
\text { congelada? }\end{array}$ \\
\hline & & $\begin{array}{l}\text { Preg 2: Según su experiencia, considera que las empresas } \\
\text { exportadoras peruanas de productos agroindustriales tienen } \\
\text { conocimiento de los requisitos técnicos para poder ingresar al } \\
\text { mercado estadounidense. }\end{array}$ \\
\hline & & $\begin{array}{l}\text { Preg 3: Teniendo en cuenta que USA es uno de los principales } \\
\text { destinos de exportación, ¿considera Ud. que el Estado peruano a } \\
\text { través de las entidades correspondientes hace énfasis en la } \\
\text { difusión de los requisitos o medidas técnicas para la exportación } \\
\text { de productos agroindustriales? }\end{array}$ \\
\hline & & $\begin{array}{l}\text { Preg 4: ¿Existe alguna barrera o limitación a la exportación de } \\
\text { pulpa de tuna congelada hacia Estados Unidos? }\end{array}$ \\
\hline & & $\begin{array}{l}\text { Preg 5: Según su opinión, ¿considera que a raíz de temas } \\
\text { políticos (terrorismo), las leyes norteamericanas se han tornado } \\
\text { más estrictas para la importación de productos agroindustriales? }\end{array}$ \\
\hline & & $\begin{array}{l}\text { Preg 6: A través del APC (Acuerdo de Promoción Comercial } \\
\text { entre Perú y USA), ¿considera que ha habido alguna mejora en } \\
\text { procedimiento técnico de exportación de productos } \\
\text { agroindustriales? ¿Considera que antes existían mayores trabas } \\
\text { técnicas? }\end{array}$ \\
\hline
\end{tabular}




\subsection{Cuestionario de la entrevista: sector privado}

\begin{tabular}{|c|c|c|}
\hline $\mathbf{N}^{\circ}$ & Dimensiones & Actores grupo 2: sector privado \\
\hline \multirow{8}{*}{1} & \multirow{8}{*}{$\begin{array}{l}\text { Análisis situacional de } \\
\text { exportación }\end{array}$} & $\begin{array}{l}\text { Preg 1: ¿Cómo ha observado la evolución de las exportaciones } \\
\text { de productos no tradicionales } \\
\text { agroexportaciones durante los últimos } 5 \text { años? }\end{array}$ \\
\hline & & $\begin{array}{l}\text { Preg 2: ¿Cómo ve el comportamiento del mercado respecto a la } \\
\text { exportación de pulpa de tuna congelada? ¿prevé un crecimiento? }\end{array}$ \\
\hline & & $\begin{array}{l}\text { Preg 3: ¿Se ha establecido algún tipo de alianza entre el sector } \\
\text { público y privado para la difusión de este producto? Si es sí } \\
\text { ¿Cuáles son? Si es no ¿Qué estrategias se podrían desarrollar } \\
\text { para promover la exportación de este producto? }\end{array}$ \\
\hline & & $\begin{array}{l}\text { Preg 4: Actualmente, ¿asisten a ferias internacionales? ¿Cuáles? } \\
\text { ¿considera la participación a ferias y misiones comerciales como } \\
\text { parte importante para la promoción de este producto? }\end{array}$ \\
\hline & & $\begin{array}{l}\text { Preg 5: ¿Por qué un importador de tuna congelada consideraría a } \\
\text { nuestro país como alternativa de proveedor teniendo en cuenta } \\
\text { que México es el principal productor y exportador de tuna? }\end{array}$ \\
\hline & & $\begin{array}{l}\text { Preg 6: ¿Considera que existe potencial para la producción y } \\
\text { exportación de la tuna industrializada? ¿Qué ventajas tiene el } \\
\text { cultivo de esta fruta en comparación a otros? }\end{array}$ \\
\hline & & $\begin{array}{l}\text { Preg 7: En torno al fruto de la tuna, ¿qué objetivos se han } \\
\text { alcanzado a través de los programas que Sierra y Selva } \\
\text { Exportadora lleva a cabo (planes de negocio, promoción y } \\
\text { difusión, capacitaciones)? }\end{array}$ \\
\hline & & $\begin{array}{l}\text { Preg } 8: ¿ \text { Cuáles considera son los principales temas en los que se } \\
\text { debe trabajar para desarrollar el sector de la tuna de manera más } \\
\text { competitiva en las principales zonas de producción? }\end{array}$ \\
\hline \multirow{8}{*}{2} & \multirow{8}{*}{$\begin{array}{l}\text { Logística de entrada } y \\
\text { salida }\end{array}$} & $\begin{array}{l}\text { Preg 1: ¿Qué inconvenientes encuentra en el traslado de la tuna } \\
\text { hacia las plantas de producción? }\end{array}$ \\
\hline & & $\begin{array}{l}\text { Preg 2: ¿Compra directamente la fruta al agricultor o la realiza a } \\
\text { través de una asociación? ¿De qué depende (origen, precio, } \\
\text { variedad)? }\end{array}$ \\
\hline & & $\begin{array}{l}\text { Preg 3: Teniendo en cuenta el inicio de operaciones de la } \\
\text { exportación de pulpa de tuna, ¿Cuál es su opinión respecto a la } \\
\text { evolución de oferta y demanda de tuna en el mercado local? }\end{array}$ \\
\hline & & $\begin{array}{l}\text { Preg 4: Basado en su experiencia, ¿Qué aspecto considera usted } \\
\text { más crítico en la exportación de pulpa de tuna congelada? }\end{array}$ \\
\hline & & $\begin{array}{l}\text { Preg 5: ¿Qué tipo de contenedor se utiliza para la exportación de } \\
\text { pulpa de tuna congelada - indicar características? Basada en la } \\
\text { pregunta anterior ¿La disponibilidad de este tipo de contenedor } \\
\text { es accesible o presenta dificultades? }\end{array}$ \\
\hline & & $\begin{array}{l}\text { Preg 6: Dentro de la documentación de exportación, ¿existe } \\
\text { algún documento trascendental que sin ello la entrega de la } \\
\text { carga se vea afectada? }\end{array}$ \\
\hline & & Preg 7: ¿Cuáles son los principales puertos de destino? \\
\hline & & Preg 8: ¿conoce usted alguna medida no arancelaria que está \\
\hline
\end{tabular}




\begin{tabular}{|c|c|c|}
\hline & & sujeta la exportación de pulpa de tuna congelada a USA? \\
\hline & & $\begin{array}{l}\text { Preg 9: ¿Cómo relaciona a los factores logísticos con la } \\
\text { competitividad en la exportación de pulpa de tuna congelada? }\end{array}$ \\
\hline \multirow{12}{*}{3} & \multirow{12}{*}{$\begin{array}{l}\text { Requisitos técnicos y } \\
\text { de calidad }\end{array}$} & $\begin{array}{l}\text { Preg 1: Según su experiencia, ¿cree usted que las barreras } \\
\text { arancelarias y no arancelarias son verdaderos obstáculos para } \\
\text { desarrollar el potencial exportador de la pulpa de tuna } \\
\text { congelada? }\end{array}$ \\
\hline & & $\begin{array}{l}\text { Preg 2: Según su experiencia, considera que las empresas } \\
\text { exportadoras peruanas de productos agroindustriales tienen } \\
\text { conocimiento de los requisitos técnicos para poder ingresar al } \\
\text { mercado estadounidense. }\end{array}$ \\
\hline & & $\begin{array}{l}\text { Preg 3: Teniendo en cuenta que USA es uno de los principales } \\
\text { destinos de exportación, considera Ud. que el Estado peruano a } \\
\text { través de las entidades correspondientes hace énfasis en la } \\
\text { difusión de los requisitos o medidas técnicas para la exportación } \\
\text { de productos agroindustriales }\end{array}$ \\
\hline & & $\begin{array}{l}\text { Preg 4: ¿Existe alguna barrera o limitación a la exportación de } \\
\text { pulpa de tuna congelada hacia Estados Unidos? }\end{array}$ \\
\hline & & $\begin{array}{l}\text { Preg 5: Según su opinión, ¿considera que a raíz de temas } \\
\text { políticos (terrorismo), las leyes norteamericanas se han tornado } \\
\text { más estrictas para la importación de productos agroindustriales? }\end{array}$ \\
\hline & & $\begin{array}{l}\text { Preg 6: A través del APC (Acuerdo de promoción comercial } \\
\text { entre Perú y USA), ¿considera que ha habido alguna mejora en } \\
\text { procedimiento técnico de exportación de productos } \\
\text { agroindustriales? ¿Considera que antes existían mayores trabas } \\
\text { técnicas? }\end{array}$ \\
\hline & & $\begin{array}{l}\text { Preg 7: ¿Cuáles son los puntos críticos para la elaboración de la } \\
\text { pulpa de tuna congelada? }\end{array}$ \\
\hline & & $\begin{array}{l}\text { Preg 8: ¿Qué estándares de calidad se toman en cuenta para la } \\
\text { elaboración de la pulpa de tuna? }\end{array}$ \\
\hline & & $\begin{array}{l}\text { Preg 9: ¿Qué tan importante, según su experiencia, considera las } \\
\text { certificaciones? ¿Cuenta la empresa con alguna certificación? } \\
\text { ¿Cuáles? }\end{array}$ \\
\hline & & $\begin{array}{l}\text { Preg 10: Para el proceso productivo de pulpas y/o derivados de } \\
\text { frutas ¿existe un lineamiento que sirva de guía? }\end{array}$ \\
\hline & & $\begin{array}{l}\text { Preg 11: Una vez obtenido el producto terminado ¿Qué tipo de } \\
\text { análisis se llevan a cabo?; de no cumplirse con los estándares de } \\
\text { calidad exigidos por el cliente ¿de qué manera proceden? }\end{array}$ \\
\hline & & $\begin{array}{l}\text { Preg 12: ¿Cuentan ustedes con apoyo técnico para el cultivo de } \\
\text { tuna? }\end{array}$ \\
\hline
\end{tabular}




\subsection{Cuestionario de la entrevista: sector experto}

\begin{tabular}{|c|c|c|}
\hline $\mathbf{N}^{\circ}$ & Dimensiones & Actores grupo 3: sector experto \\
\hline \multirow{14}{*}{1} & \multirow{14}{*}{$\begin{array}{l}\text { Producción y Oferta } \\
\text { Exportable }\end{array}$} & $\begin{array}{l}\text { Preg 1: ¿Cómo ha observado la evolución de las exportaciones } \\
\text { de productos no tradicionales específicamente } \\
\text { agroexportaciones durante los últimos } 5 \text { años? }\end{array}$ \\
\hline & & $\begin{array}{l}\text { Preg 2: ¿Cómo ve el comportamiento del mercado respecto a la } \\
\text { exportación de pulpa de tuna congelada? ¿prevé un crecimiento? }\end{array}$ \\
\hline & & $\begin{array}{l}\text { Preg 3: ¿Se ha establecido algún tipo de alianza entre el sector } \\
\text { público y privado para la difusión de este producto? Si es sí } \\
\text { ¿Cuáles son? Si es no ¿Qué estrategias se podrían desarrollar } \\
\text { para promover la exportación de este producto? }\end{array}$ \\
\hline & & $\begin{array}{l}\text { Preg 4: Teniendo en cuenta los beneficios nutricionales de la } \\
\text { tuna ¿cuáles son los motivos por los que no está considerada } \\
\text { dentro de la categoría de Super Fruits? }\end{array}$ \\
\hline & & $\begin{array}{l}\text { Preg 5: Actualmente, ¿asisten a ferias internacionales? ¿Cuáles? } \\
\text { ¿considera la participación a ferias y misiones comerciales como } \\
\text { parte importante para la promoción de este producto? }\end{array}$ \\
\hline & & $\begin{array}{l}\text { Preg 6: ¿Por qué un importador de tuna congelada consideraría a } \\
\text { nuestro país como alternativa de proveedor teniendo en cuenta } \\
\text { que México es el principal productor y exportador de tuna? }\end{array}$ \\
\hline & & $\begin{array}{l}\text { Preg 7: ¿Qué papel desempeñan las OCEX’s? ¿Dentro de sus } \\
\text { funciones se encuentra el análisis de mercados? }\end{array}$ \\
\hline & & $\begin{array}{l}\text { Preg 8: Cuáles son las regiones productoras más importantes de } \\
\text { tuna? }\end{array}$ \\
\hline & & $\begin{array}{l}\text { Preg 9: ¿Cuáles son las expectativas de producción del sector de } \\
\text { la tuna para los próximos tres años? }\end{array}$ \\
\hline & & $\begin{array}{l}\text { Preg 10: ¿Cuál es la situación actual de las zonas productoras de } \\
\text { tuna? }\end{array}$ \\
\hline & & $\begin{array}{l}\text { Preg 11: ¿Existen asociaciones y/o cooperativas de productores } \\
\text { de tuna? }\end{array}$ \\
\hline & & $\begin{array}{l}\text { Preg 12: ¿Considera que existe potencial para la producción y } \\
\text { exportación de la tuna industrializada? ¿Qué ventajas tiene el } \\
\text { cultivo de esta fruta en comparación a otros? }\end{array}$ \\
\hline & & $\begin{array}{l}\text { Preg 13: En torno al fruto de la tuna, ¿qué objetivos se han } \\
\text { alcanzado a través de los programas que Sierra y Selva } \\
\text { Exportadora lleva a cabo (planes de negocio, promoción y } \\
\text { difusión, capacitaciones)? }\end{array}$ \\
\hline & & $\begin{array}{l}\text { Preg 14: ¿Cuáles considera son los principales temas en los que } \\
\text { se debe trabajar para desarrollar el sector de la tuna de manera } \\
\text { más competitiva en las principales zonas de producción? }\end{array}$ \\
\hline \multirow[t]{2}{*}{3} & \multirow{2}{*}{$\begin{array}{l}\text { Requisitos técnicos y } \\
\text { de calidad }\end{array}$} & $\begin{array}{l}\text { Preg 1: Según su experiencia, ¿cree usted que las barreras } \\
\text { arancelarias y no arancelarias son verdaderos obstáculos para } \\
\text { desarrollar el potencial exportador de la pulpa de tuna } \\
\text { congelada? }\end{array}$ \\
\hline & & $\begin{array}{l}\text { Preg 2: Según su experiencia, considera que las empresas } \\
\text { exportadoras peruanas de productos agroindustriales tienen } \\
\text { conocimiento de los requisitos técnicos para poder ingresar al }\end{array}$ \\
\hline
\end{tabular}


mercado estadounidense.

Preg 3: Teniendo en cuenta que USA es uno de los principales destinos de exportación, ¿considera Ud. que el Estado peruano a través de las entidades correspondientes hace énfasis en la difusión de los requisitos o medidas técnicas para la exportación de productos agroindustriales?

Preg 4: ¿Existe alguna barrera o limitación a la exportación de pulpa de tuna congelada hacia Estados Unidos?

Preg 5: Según su opinión, ¿considera que a raíz de temas políticos (terrorismo), las leyes norteamericanas se han tornado más estrictas para la importación de productos agroindustriales?

Preg 6: A través del APC (Acuerdo de Promoción Comercial entre Perú y USA), ¿considera que ha habido alguna mejora en procedimiento técnico de exportación de productos agroindustriales? ¿Considera que antes existían mayores trabas técnicas? 
1.4. Cuestionario de la entrevista: sector productor y/o acopiador

\begin{tabular}{|c|c|c|}
\hline $\mathbf{N}^{\circ}$ & Dimensiones & Actores grupo 4: agricultor y/o acopiador \\
\hline \multirow{6}{*}{1} & \multirow{6}{*}{$\begin{array}{l}\text { Análisis situacional de } \\
\text { exportación }\end{array}$} & $\begin{array}{l}\text { Preg 1: Teniendo en cuenta que, de la planta de la tuna, se puede } \\
\text { obtener bien sea el fruto (tuna) o tinte (cochinilla); ¿qué factor } \\
\text { determina para que el agricultor opte por uno de ellos? }\end{array}$ \\
\hline & & $\begin{array}{l}\text { Preg 2: ¿Cómo se comporta el precio de la tuna, de que depende } \\
\text { principalmente? ¿Qué rol juega la cochinilla? }\end{array}$ \\
\hline & & $\begin{array}{l}\text { Preg 3: ¿Conoce usted de alguna entidad del estado y/o privada } \\
\text { que se encargue de fomentar y/o supervisar la producción de } \\
\text { tuna? }\end{array}$ \\
\hline & & $\begin{array}{l}\text { Preg 4: ¿Cómo ha observado usted la demanda de la tuna? } \\
\text { ¿Considera que ha ido en aumento o se ha mantenido a lo largo } \\
\text { de estos últimos } 5 \text { años? }\end{array}$ \\
\hline & & Preg 5: ¿De qué zonas usted acopia la tuna? \\
\hline & & $\begin{array}{l}\text { Preg 6: ¿Desde hace cuánto tiempo acopia tuna para empresas } \\
\text { agroexportadoras? }\end{array}$ \\
\hline 2 & $\begin{array}{l}\text { Logística de entrada y } \\
\text { salida }\end{array}$ & $\begin{array}{l}\text { Preg 1: ¿Qué inconvenientes encuentra en el traslado de la tuna } \\
\text { hacia las plantas de producción? }\end{array}$ \\
\hline 3 & $\begin{array}{l}\text { Requisitos técnicos y } \\
\text { de calidad }\end{array}$ & $\begin{array}{l}\text { Preg 1: ¿Cuentan ustedes con apoyo técnico para el cultivo de } \\
\text { tuna? }\end{array}$ \\
\hline
\end{tabular}

